\title{
Complement Component Clq Mediates Mitochondria-Driven Oxidative Stress in Neonatal Hypoxic-Ischemic Brain Injury
}

\author{
Vadim S. Ten, ${ }^{1}$ Jun Yao, ${ }^{1}$ Veniamin Ratner, ${ }^{1}$ Sergey Sosunov, ${ }^{2}$ Deborah A. Fraser, ${ }^{4}$ Marina Botto, ${ }^{5}$ \\ Baalasubramanian Sivasankar, ${ }^{6}$ B. Paul Morgan, ${ }^{6}$ Samuel Silverstein, ${ }^{3}$ Raymond Stark, ${ }^{1}$ Richard Polin, ${ }^{1}$ \\ Susan J. Vannucci, ${ }^{8}$ David Pinsky, ${ }^{7}$ and Anatoly A. Starkov ${ }^{9}$ \\ Departments of ${ }^{1}$ Pediatrics, ${ }^{2}$ Neurosurgery, and ${ }^{3}$ Physiology and Cellular Biophysics, Columbia University, New York, New York 10032, ${ }^{4}$ Department of \\ Molecular Biology and Biochemistry, University of California Irvine, Irvine, California 92697, ${ }^{5}$ Rheumatology Section, Faculty of Medicine, Imperial \\ College, London SW7 2AZ, United Kingdom, ${ }^{6}$ Department of Medical Biochemistry and Immunology, Cardiff University, Cardiff CF14 4XN, United \\ Kingdom, ${ }^{7}$ Department of Medicine, University of Michigan, Ann Arbor, Michigan 48109, and Departments of ${ }^{8}$ Pediatrics and ${ }^{9}$ Neurology, Cornell \\ University, New York, New York 10021
}

Hypoxic-ischemic (HI) brain injury in infants is a leading cause of lifelong disability. We report a novel pathway mediating oxidative brain injury after hypoxia-ischemia in which $\mathrm{Clq}$ plays a central role. Neonatal mice incapable of classical or terminal complement activation because of $\mathrm{Clq}$ or $\mathrm{C} 6$ deficiency or pharmacologically inhibited assembly of membrane attack complex were subjected to hypoxia-ischemia. Only $\mathrm{Clq}^{-1-}$ mice exhibited neuroprotection coupled with attenuated oxidative brain injury. This was associated with reduced production of reactive oxygen species (ROS) in $\mathrm{Clq}^{-l-}$ brain mitochondria and preserved activity of the respiratory chain. Compared with $\mathrm{Clq}^{+/+}$neurons, cortical Clq ${ }^{-/-}$neurons exhibited resistance to oxygen-glucose deprivation. However, postischemic exposure to exogenous $\mathrm{Clq}$ increased both mitochondrial ROS production and mortality of $\mathrm{Clq}^{-1-}$ neurons. This $\mathrm{Clq}$ toxicity was abolished by coexposure to antioxidant Trolox (6-hydroxy-2,5,7,8-tetramethylchroman-2-carboxylic acid). Thus, the C1q component of complement, accelerating mitochondrial ROS emission, exacerbates oxidative injury in the developing HI brain. The terminal complement complex is activated in the $\mathrm{HI}$ neonatal brain but appeared to be nonpathogenic. These findings have important implications for design of the proper therapeutic interventions against $\mathrm{HI}$ neonatal brain injury by highlighting a pathogenic priority of $\mathrm{Clq}$-mediated mitochondrial oxidative stress over the $\mathrm{Clq}$ deposition-triggered terminal complement activation.

\section{Introduction}

Accumulating evidence indicate that complement (C) activation contributes to ischemia-reperfusion injury in different organs (Pedersen et al., 2004; Arumugam et al., 2006). We have reported that neonatal mice with genetic deletion of $\mathrm{Clq}$, the initial component of classical $\mathrm{C}$ activation pathway, were protected against hypoxic-ischemic (HI) brain injury (Ten et al., 2005). Clq is essential for activation of the classical C pathway, which results in assembly of cytotoxic membrane attack complex (MAC) (Trouw et al., 2008). In the heart and kidney, an ischemic insult results in robust activation of classical C pathway and deposition of MAC in the injured tissue, suggesting a pathogenic role for the terminal C complex in tissue damage (Vakeva et al., 1998; Zhou et al., 2000; Yamada et al., 2004). The evidence for a deleterious role of terminal $\mathrm{C}$ activation in perinatal cerebral $\mathrm{HI}$ injury is controversial. Systemic C depletion with cobra venom factor significantly

Received 0ct. 22, 2009; revised Dec. 1, 2009; accepted Dec. 10, 2009.

This work was supported by National Institutes of Health Grants NS 046156 (V.S.T.) and NS 065396 (A.A.S.). B.P.M. and S.B. were supported by the Welcome Trust Programme 068590. Weare thankful to Dr. Robert Winchester for helpful discussion, Dr. Irina Utkina-Sosunova for excellent technical assistance, and Dr. A. Ratner for the help with live-cell imaging.

Correspondence should be addressed to Dr. Vadim S. Ten, Division of Neonatology, Department of Pediatrics, Columbia University, 3959 Broadway, CHN 1201, New York, NY 10032. E-mail: vt82@columbia.edu.

DOI:10.1523/JNEUROSCI.5249-09.2010

Copyright $\odot 2010$ the authors $\quad 0270-6474 / 10 / 302077-11 \$ 15.00 / 0$ attenuated HI brain damage in neonatal rats. However, the cerebral expression of $\mathrm{C} 9$, a marker for MAC assembly, in the $\mathrm{C}$-depleted rats was similar to that in the vehicle-treated littermates (Cowell et al., 2003), arguing against a pathogenic role of MAC in HI injury. In contrast, an association between cerebral C9 deposition and the severity of brain injury has been reported in HI rats and asphyxiated infants (Figueroa et al., 2005; Schultz et al., 2005). Pretreatment with exogenous C9 exacerbated HI brain injury in immature rats deficient in C9 (Imm et al., 2002). Furthermore, human cultured neurons incubated with antiCD59 antibodies were susceptible to MAC-driven cytolysis after spontaneous activation of the classical C pathway (Singhrao et al., 2000). This suggests that C1q mediates HI brain injury via classical $\mathrm{C}$ pathway activation resulting in MAC-driven exacerbation of cell damage during reperfusion.

It has been shown that incubation of cultured cortical neurons with human $\mathrm{Clq}$ induced a lethal oxidative stress (Luo et al., 2003). Given that mitochondria are primary source of reactive oxygen species (ROS), we hypothesized that C1q may exacerbate HI brain damage by affecting mitochondrial ROS generation.

In this study, we tested two alternative hypotheses: (1) neonatal HI brain injury is mediated by Clq-dependent terminal C activation or (2) C1q directly (independently from C activation pathway) exacerbates HI brain injury by potentiating the severity of mitochondria-mediated oxidative stress. 


\section{Materials and Methods}

Mice. C1q $\alpha$ knock-out $\left(\mathrm{Clq}^{-1-}\right)$, C6-deficient $\left(\mathrm{C}^{-1-}\right)$ mice backcrossed into C57BL/6 strain for 10 and 5 generations (Botto et al., 1998; Morgan et al., 2006) and wild-type (WT) mice (C57BL/6J purchased from The Jackson Laboratory) were bred in the animal facility of Columbia University. The experimental protocol was approved by the Institutional Animal Care and Use Committee of Columbia University.

Induction of unilateral hypoxia-ischemia. We used the Rice-Vannucci model of HI brain injury adapted to postnatal day 9 (P9) to P10 neonatal mice (Ten et al., 2003, 2004). The model consisted of a permanent ligation of the right carotid artery followed by hypoxic exposure. Briefly, surgical intervention was performed under isoflurane anesthesia. At $1.5 \mathrm{~h}$ of recovery, pups were exposed to hypoxia $\left(8 \% \mathrm{O}_{2}\right.$ balanced $\left.\mathrm{N}_{2}\right)$ for 15 min. The ambient temperature during hypoxia was maintained at $37.0-$ $37.5^{\circ} \mathrm{C}$ by placing the hypoxic chamber in a neonatal isolette (Airshield). After hypoxic exposure, pups were returned to their dams. To minimize a temperature-related variability in the extent of brain injury, during the initial $12 \mathrm{~h}$ of reperfusion, mice were kept in an isolette at the ambient $t=$ $32^{\circ} \mathrm{C}$. In adult male mice, hypoxia-ischemia was produced as described above, except the ambient temperature during hypoxia was maintained at $35.5-36^{\circ} \mathrm{C}$, and the duration of hypoxia was extended to $25 \mathrm{~min}$. The modulation of hypoxic duration with the age was shown to produce a similar degree of injury in neonatal or juvenile or adult mice with minimal changes in mortality (Lafemina et al., 2006; Zhu et al., 2009). At $24 \mathrm{~h}$ of reperfusion, mice were killed by decapitation, and brains were harvested, sectioned into 1-mm-thick coronal slices, and stained with $2 \%$ triphenyl-tetrazolium chloride (TTC). TTC is oxidized only by metabolically active mitochondrial dehydrogenases converting TTC into a redcolored formazan (Schinzel et al., 2005). Digital images of infarcted (pale white) and viable (red) areas of brains were traced (Adobe Photoshop 4.0.1) and analyzed (NIH Image 1.62) by an investigator "blinded" to a genotype identity. The extent of brain injury (direct infarct volume) was expressed as a percentage of the infarcted hemisphere ipsilateral to the carotid artery ligation.

Clq and MAC in HI injury. To investigate the role of Clq and MAC in $\mathrm{HI}$ brain injury, the progenies of $\mathrm{Clq}^{+/-}$or $\mathrm{Clq}^{+/-}$and $\mathrm{Clq}^{-1-}$ mating (cohort 1), $\mathrm{Clq}^{-1-}$ along with age- and strain-matched C6-deficient and WT mice (cohort 2) simultaneously were subjected to hypoxiaischemia. $\mathrm{Clq}^{-1-}$ mice are not able to activate terminal $\mathrm{C}$ via the classical $\mathrm{C}$ activation pathway. The $\mathrm{C}^{-1-}$ mice lack one (C6) of the components of MAC (C5b-C9) and are not able to assemble a functional terminal C complex (MAC). Therefore, if C1q-dependent (classical pathway) activation of the terminal $\mathrm{C}$ complex participates in $\mathrm{HI}$ injury, then both $\mathrm{C} 1 \mathrm{q}^{-/-}$and $\mathrm{C}^{-1-}$ mice are expected to demonstrate neuroprotection. The extent of cerebral damage was analyzed after C1q genotyping.

C1q genotyping. C1qa primers were as follows: $\mathrm{mClqa} / 5+$, GGG GCC TGT GAT CCA GAC AG; mC1qIN/2-, TAA CCA TTG CCT CCA GGA TGG; Neo3', GGG GAT CGG CAA TAA AAA GAC. The deficiency of C6 $\left(\mathrm{C}^{-1-}\right)$ in mice was verified functionally by the assessment of C6dependent hemolytic activity of human serum (Kabad and Mayer, 1961). Briefly, in $500 \mu$ l of gelatin Veronal buffer (Sigma-Aldrich), an increasing concentration of serum obtained from $\mathrm{P} 10$ naive $\mathrm{WT}$ or $\mathrm{C6}^{-1-}$ mice was incubated with sensitized sheep erythrocytes $\left(3 \times 10^{7}\right.$; Sigma-Aldrich $)$ in the presence of human C6-deficient serum ( $25 \mu \mathrm{l}$; Sigma-Aldrich) for 30 $\min$ at $37^{\circ} \mathrm{C}$. Hemolytic activity of each sample was measured at $412 \mathrm{~nm}$ to obtain hemolytic titration curve. Using this curve, the amount of WT mouse $\left(\mathrm{C}^{+/+}\right)$serum $(20 \mu \mathrm{l})$ that restored $50-60 \%$ of hemolytic activity of C6-deficient serum was determined. Then hemolytic activity of serum $(20 \mu \mathrm{l})$ obtained from randomly selected $\mathrm{C}^{-/-}$and WT HI mice were compared and expressed as percentage of hemolysis relative to the extent of spontaneous hemolysis (0\%) and osmotic hemolysis (100\%).

A separate cohort of WT mice was used to determine whether pharmacological inhibition of MAC assembly attenuates the extent of HI brain injury. At $12 \mathrm{~h}$ before HI insult, WT mice were pretreated either with mouse-specific IgG-fused soluble CD59 (sCD59) (200 $\mu$ g, i.p., in $0.15 \mathrm{ml}$ of PBS) or vehicle ( $0.15 \mathrm{ml}$ of PBS, i.p.) followed by the exposure to $\mathrm{HI}$ insult as described previously. At $24 \mathrm{~h}$ of reperfusion, brains were examined for the degree of $\mathrm{C} 9$ deposition and the extent of HI injury.
sCD59 is a potent primary inhibitor of MAC assembly on cell membranes in mice (Baalasubramanian et al., 2004). Pretreatment with sCD59 has been shown to limit the assembly of MAC (decreased deposition of C9) in the renal tissue after ischemia-reperfusion, and this was associated with attenuation of injury (Yamada et al., 2004).

Extent of $C$ activation. The extent of $\mathrm{C}$ activation was assessed by detection of C3-split products and C9 in the post-HI brains. Briefly, at $24 \mathrm{~h}$ after $\mathrm{HI}$ insult, brains were harvested from randomly selected $\mathrm{Clq}^{-1-}$, $\mathrm{C} 1 \mathrm{q}^{+/+}$mice and the WT mice pretreated with SCD59 or vehicle, fixed in $4 \%$ paraformaldehyde, and incubated with rabbit/anti-rat C9 antibodies or rat/anti-mouse monoclonal antibodies against $\mathrm{C} 3 \mathrm{~b} / \mathrm{iC} 3 \mathrm{~b} / \mathrm{C} 3 \mathrm{c}$ neoepitopes (Hycult Biotechnology). Rabbit/anti-rat C9 antibodies crossreact with mouse $\mathrm{C} 9$ and have been used as a marker for MAC assembly and cellular deposition after renal and brain injury in mice (Yamada et al., 2004; Alexander et al., 2005). Nissl and microtubule-associated protein 2 (MAP2) (1:800; Sigma-Aldrich) staining were used to counterstain nucleus and neuronal cytosol. During confocal microscopy (Bio-Rad 2000 laser-scanning device; Nikon E800), the infarcted areas of brain were identified by the regional loss of MAP2 immunoreactivity. The level of immunopositivity for C9 and C3-split products was assessed semiquantitatively as described previously (Ten et al., 2005). Images of the area of interest (ipsilateral and contralateral hemisphere) were captured under identical fluorescence and magnification. Areas (in pixels) positive for C9 and C3-split products were measured using Image-Pro Plus 4.5 (Media Cybernetics). A total of five nonadjacent fields in five cerebral sections $(-1$ to $+1.5 \mathrm{~mm}$ in relation to bregma) were analyzed from each mouse. Mean value of immunopositivity (pixels) for C9 and C3-split products obtained from a single mouse was used for data analysis. In addition, the presence of $\mathrm{C} 3 \mathrm{~d}$ (C3-split product) in the ischemic brains was quantified by Western blot analysis as described previously (Mack et al., 2006). In brief, $50 \mu \mathrm{g}$ of total protein per sample were denaturated in SDS with reducing agent and run on NuPAGE Novex 12\% Bis-Tris Gel (Invitrogen) under reducing conditions. Membranes were incubated with the goat anti-mouse C3d antibody (1:1000; R\&D Systems) followed by incubation with horseradish peroxidase (HRP)-conjugated donkey anti-goat secondary antibody (1:20,000). Immunoreactive bands were detected using a chemiluminescence kit (Thermo Fisher Scientific), and membranes were exposed to x-ray film (Eastman Kodak). Blots were scanned and analyzed using NIH ImageJ to quantify relative (normalized to $\beta$-actin) expression of $\mathrm{C} 3 \mathrm{~d}$. The ratio of $\mathrm{C} 3 \mathrm{~d}$ optical density between ipsilateral and contralateral hemisphere was used for statistical analysis.

Neuronal C1q genotype and oxygen-glucose deprivation. Cortical neurons were isolated from mouse fetal brains at $16 \mathrm{~d}$ of gestation as described previously (Brewer et al., 1993; Takuma et al., 2005). Briefly, the cerebral cortex from $\mathrm{WT}$ and $\mathrm{Clq}^{-/-}$fetuses was removed, digested with trypsin (Invitrogen), and triturated in the Neurobasal media supplemented with $2 \%$ B27, $0.5 \mathrm{~mm}$ glutamine, and $4.4 \mathrm{~mm}$ sodium bicarbonate. Isolated cortical neurons in $1 \mathrm{ml}$ of the media were centrifuged $\left(3000 \times \mathrm{g} ; 3 \mathrm{~min}\right.$; at $\left.4^{\circ} \mathrm{C}\right)$, and pellets were resuspended in the Neurobasal/B27 media supplemented with $0.5 \mathrm{~mm}$ glutamine, $50 \mathrm{U} / \mathrm{ml}$ penicillin, and $50 \mathrm{mg} / \mathrm{ml}$ streptomycin. Then cells were seeded in the 24 -well plates (Corning Life Sciences) precoated with $50 \mathrm{mg} / \mathrm{ml}$ poly-L-lysine (Invitrogen) at a density of $1 \times 10^{5}$ cells per well. After $3-4 \mathrm{~d}$ in vitro incubation at $37^{\circ} \mathrm{C}$ and $5 \% \mathrm{CO}_{2}$, neurons were subjected to the oxygenglucose deprivation (OGD) stress.

OGD challenge. OGD challenge was produced as described previously (Zhang et al., 2003; Benchenane et al., 2005). In brief, the neurons were washed with HBSS, rinsed with PBS, and incubated in glucose-free DMEM media prebubbled with hypoxic gas mixture $\left(94 \% \mathrm{~N}_{2}\right.$ plus $6 \%$ $\mathrm{CO}_{2}$ at $\mathrm{pH}$ 7.4) in the tightly sealed plastic chamber containing anaerobic GasPak EZ Container System and $\mathrm{O}_{2}$ indicator (BD Biosciences). The GasPak EZ system contains a reagent sachet consisting of inorganic carbonate, activated carbon, ascorbic acid, and water. When the sachet is removed from the outer wrapper, it is activated by the exposure to air and rapidly reduces the oxygen concentration within the chamber to $<1 \%$. The $\mathrm{O}_{2}$ indicator changes color (white to blue) if $\mathrm{O}_{2}$ concentration in the chamber exceeds $1 \%$. The OGD was carried for $4 \mathrm{~h}$ at $37^{\circ} \mathrm{C}$. After OGD cells were replenished with fresh media and kept at standard (normoxia; $5 \% \mathrm{CO}_{2}$; at $37^{\circ} \mathrm{C}$ ) condition for reperfusion. At $20 \mathrm{~h}$ of reperfusion, 
cellular viability was assessed using 3-(4,5-dimethylthiazol-2-yl)-2,5diphenyltetrazolium bromide (MTT) reducing assay. Briefly, cells were washed with HBSS and incubated in the same media containing $5 \mathrm{mg} / \mathrm{ml}$ MTT and $10 \mathrm{~mm}$ sodium succinate. After $60 \mathrm{~min}$ of incubation, the media was removed and cells were rinsed with PBS and dried. The formazan crystals were solubilized with $0.3 \mathrm{ml}$ of $4 \mathrm{~mm} \mathrm{HCl}$-isopropanol. The plates were read on the Tecan microplate reader (Infinite M200) at a wavelength of $570 \mathrm{~nm}$.

To examine a direct effect of C1q on cellular survival during reperfusion, $\mathrm{Clq}^{-1-}$ neurons were exposed to increasing concentrations $(0.035-1.75 \mu \mathrm{g} / \mathrm{ml})$ of purified human C1q protein (hC1q) produced as described previously (Tenner et al., 1981) or purchased (Quidel). The concentration of C1q in human CSF averages $0.340 \mu \mathrm{g} / \mathrm{ml}$ (Smyth et al., 1994). Given that, after a global cerebral ischemia, Clq is dramatically upregulated leading to a threefold to sixfold increase in C1q-dependent hemolytic activity (Schäfer et al., 2000), we selected hC1q doses representing normal and elevated C1q concentration in CSF, 0.35 to 1.75 $\mu \mathrm{g} / \mathrm{ml}$. Cellular viability in WT and $\mathrm{Clq}^{-1-}$ OGD-stressed neurons was assessed after reperfusion in the presence or absence of $200 \mu \mathrm{M}$ 6-hydroxy-2,5,7,8-tetramethylchroman-2-carboxylic acid (Trolox), a potent ROS scavenger. Cellular viability of OGD-stressed cells was expressed as percentage in the relation to the viability of genotypeappropriate untreated neurons (100\%). Data from four separate experiments were used for analysis.

Assays for mitochondrial functions. To determine whether the presence or absence of $\mathrm{Clq}$ alters the response of brain mitochondria to $\mathrm{HI}$ insult, separate cohorts of $\mathrm{Clq}^{-/-}$and $\mathrm{Clq}^{+/+}$mice were subjected to hypoxia-ischemia as described previously. Brain nonsynaptosomal mitochondria were isolated as described previously (Caspersen et al., 2008) with minor modification. The rates of mitochondrial respiration, ROS emission were measured at three different time points of reperfusion: 0, 30-60 min, and $4-6 \mathrm{~h}$, respectively. Mitochondrial membrane potential $(\Delta \psi \mathrm{m})$ was measured at 0 and 30-60 min of reperfusion.

Mitochondrial respiration. Mitochondrial respiration was measured using a Clark-type electrode (Oxytherm; Hansatech). Mitochondria $(0.05 \mathrm{mg}$ of protein) were added to $0.5 \mathrm{ml}$ of respiration buffer composed of $200 \mathrm{~mm}$ sucrose, $25 \mathrm{~mm} \mathrm{KCl}, 2 \mathrm{~mm} \mathrm{~K}_{2} \mathrm{HPO}_{4}, 5$ mM HEPES-KOH, $\mathrm{pH}$ 7.2, $5 \mathrm{mM} \mathrm{MgCl}_{2}, 0.2 \mathrm{mg} / \mathrm{ml} \mathrm{BSA}, 30 \mu \mathrm{M} P^{1}, P^{5}$-di(adenosine $5^{\prime}$ )pentaphosphate ( $\mathrm{Ap}_{5} \mathrm{~A}$ ) (an inhibitor of adenylate kinase), $10 \mathrm{~mm}$ glutamate, and $5 \mathrm{~mm}$ malate at $t=32^{\circ} \mathrm{C}$. To initiate the phosphorylating respiration (state 3), $100 \mathrm{nmol}$ of ADP was added to the mitochondrial suspension. To achieve a nonphosphorylating (uncoupled) acceleration of respiration, $70 \mu \mathrm{M}$ 2,4-dinitrophenol (DNP) was added at the state 4, after a completion of ADP phosphorylation. Rates of $\mathrm{O}_{2}$ consumption were expressed in nanomoles of $\mathrm{O}_{2}$ per milligram of mitochondrial protein per minute. The respiratory control ratio (RCR) was calculated as the ratio of the state 3 respiration rate to the resting respiration rate (state 4) recorded after the phosphorylation of ADP has been completed.

Measurement of mitochondrial $\mathrm{H}_{2} \mathrm{O}_{2}$ emission rate. Measurement of mitochondrial $\mathrm{H}_{2} \mathrm{O}_{2}$ emission rate was performed by a fluorescence assay with Hitachi 7000 spectrofluorimeter set at $555 \mathrm{~nm}$ excitation and $581 \mathrm{~nm}$ emission as described previously (Starkov and Fiskum, 2003). Briefly, mitochondria $(0.05 \mathrm{mg} / \mathrm{ml})$ were placed in $1 \mathrm{ml}$ of respiration buffer with omitted malate/glutamate and $\mathrm{Ap}_{5} \mathrm{~A}$, but supplemented with $5 \mathrm{~mm}$ succinate, $10 \mu \mathrm{M}$ Amplex Ultrared (Invitrogen), and $4 \mathrm{U} / \mathrm{ml} \mathrm{HRP.}$ After recording the fluorescence for $400 \mathrm{~s}$, samples were supplemented with $1 \mu \mathrm{M}$ rotenone and, after another $\sim 200 \mathrm{~s}$, with $1 \mu \mathrm{g} / \mathrm{ml}$ Antimycin A. The calibration curve was obtained by adding several $100 \mathrm{nmol}$ aliquots of freshly made $\mathrm{H}_{2} \mathrm{O}_{2}$ to the cuvette containing the respiration buffer, Amplex Ultrared, and HRP. The rate of $\mathrm{H}_{2} \mathrm{O}_{2}$ emission was expressed in nanomoles of $\mathrm{H}_{2} \mathrm{O}_{2}$ per milligram of mitochondrial protein per minute.

The rationale for testing mitochondrial ROS generation rate on the flavin adenine dinucleotide (FAD)-linked substrate succinate was based on studies that demonstrated $\sim 300 \%$ increase in succinate concentration in the rat brain after ischemia (Folbergrová et al., 1974; Benzi et al., 1979). In contrast, the same ischemia resulted in a profound (8- to 10fold compared with control) decrease in the concentration of mitochondrial NAD-linked substrates. This elevated cerebral level of succinate returned to the preischemic range by $30 \mathrm{~min}$ of reperfusion (Benzi et al., 1982). In mature rats, forebrain ischemia and $6 \mathrm{~h}$ of reperfusion resulted in significant inhibition of mitochondrial respiration tested on NADlinked substrates. However, no significant differences from the control values were found when the same mitochondria respired on succinate (Sims, 1991). In neonatal rats exposed to HI cerebral mitochondria exhibited a better respiration on FAD-linked than on NAD-linked substrates (Gilland et al., 1998). Together, these data indicate that, during postischemic reperfusion in mature and immature brains, the conditions are more preferable for oxidation of succinate rather than NAD-linked substrates.

Reconstitution of isolated $\mathrm{Clq}^{-1-}$ mitochondria with exogenous C1q. Reconstitution of isolated $\mathrm{Clq}^{-1-}$ mitochondria with exogenous $\mathrm{Clq}$ was performed to examine whether direct interaction of hClq with isolated mitochondria will alter mitochondrial ROS generation rate. Cerebral mitochondria isolated from naive $\mathrm{Clq}^{-1-}$ mice $(0.1 \mathrm{mg}$ of protein) were coincubated with either active or heat-inactivated hC1q ( 1.75 or 3.5 $\mu \mathrm{g} / \mathrm{ml}$ ) for $30 \mathrm{~min}$ at $37^{\circ} \mathrm{C}$ in $1 \mathrm{ml}$ of cytosol-like buffer ( $125 \mathrm{~mm} \mathrm{KCl}, 14$ $\mathrm{mm} \mathrm{NaCl}, 2 \mathrm{~mm} \mathrm{KH} \mathrm{PO}_{4}, 20 \mathrm{~mm}$ HEPES, pH 7.2, 1 mм $\mathrm{MgCl}_{2}, 4 \mathrm{~mm}$ ATP, 0.2 mM EGTA) in the cuvette with magnetic stirrer. At 20 min of incubation, Amplex Ultrared and $4 \mathrm{U} / \mathrm{ml}$ HRP were added and mitochondrial respiration was initiated with supplementation of succinate ( $5 \mathrm{~mm}$ ). The $\mathrm{H}_{2} \mathrm{O}_{2}$ emission rate was recorded for $500 \mathrm{~s}$ followed by supplementation of rotenone and antimycin-A as described above. After spectrofluorometry, mitochondria and buffer containing hC1q were centrifuged at $10,000 \times g$ for $20 \mathrm{~min}$. Then, both supernatant (buffer) and mitochondrial pellet (pellet was washed three times in the fresh buffer) were processed for Western blot analysis for the presence of hC1q.

Membrane potential. The membrane potential $(\Delta \Psi \mathrm{m})$ of isolated mitochondria was estimated using the fluorescence of Safranin O with excitation and emission wavelengths of 495 and $586 \mathrm{~nm}$, respectively (Kowaltowski et al., 2002). Mitochondria $(0.05 \mathrm{mg} / \mathrm{ml})$ were suspended in the respiration buffer supplemented with Safranin-O at 20:1 ratio (micromolar Safranin-O to milligrams of mitochondrial protein) to ensure the linearity of the dye response to $\Delta \Psi \mathrm{m}$ changes (Zanotti and Azzone, 1980).

Assessment of mitochondrial ROS scavenging capacity. An assessment of mitochondrial ROS scavenging capacity was based on measurements of total glutathione concentration (GSH), levels of glutathione peroxidase (GPx), glutathione reductase (GR), and Mn-superoxide dismutase (MnSOD) in randomly selected samples of brain mitochondria isolated from $\mathrm{Clq}^{-1-}$ and $\mathrm{Clq}^{+/+}$naive mice and $\mathrm{HI}$ mice at $4 \mathrm{~h}$ of reperfusion.

Measurement of glutathione. GSH concentrations were measured as described by Griffith (1980) with minor modification. Briefly, to prevent self-oxidation, mitochondria $(1.5 \mathrm{mg} / \mathrm{ml})$ were diluted in $5 \%$ metaphosphoric acid (1:1). Three working solutions were used as follows: (1) 0.3 mм NADPH (Sigma-Aldrich), (2) 6 mm 5,5'-dithiobis-2-nitrobenzoic acid (DTNB) (Sigma-Aldrich), and (3) $10 \mathrm{U} / \mathrm{ml}$ glutathione reductase (Sigma-Aldrich). Reduced glutathione in concentration of $0-20 \mu \mathrm{M}$ was used as standard (Sigma-Aldrich). GSH concentration was measured at $405 \mathrm{~nm}$ using a microplate reader (Tecan) and expressed in micromoles per milligram of total protein. The levels of GPx, GR, and MnSOD were quantified by Western blot analysis. Antibodies against GPx, GR, and MnSOD (Abcam) were used in final concentrations of 1:2000, 1:1000, and 1:20,000, respectively.

Complex I and citrate synthase activity. Complex I and citrate synthase (CS) activity was measured spectrophotometrically as rotenone-sensitive $\mathrm{NADH}: \mathrm{Q}_{1}$ reductase. Reaction buffer was composed of $10 \mathrm{ml}$ of $2 \mathrm{~mm}$ HEPES, pH 7.8, $75 \mu \mathrm{M} \mathrm{NADH}, 40 \mu \mathrm{M}$ coenzyme $\mathrm{Q}_{1}$ (final concentration). Frozen-thawed mitochondria $(0.1 \mathrm{mg} / \mathrm{ml})$ were mixed with the reaction buffer in a 96-well plate, and the absorbance changes at $340 \mathrm{~nm}$ were followed for $15 \mathrm{~min}$ with plate reader HTS7000 + (PerkinElmer). In control incubations, the reaction buffer was supplemented with $2 \mu \mathrm{M}$ rotenone (final concentration). The activity of complex I was calculated as difference between the rates of NADH oxidation $\left(E^{340} \mathrm{mM}=6.22\right.$ $\left.\mathrm{cm}^{-1}\right)$ in the absence and in the presence of rotenone and presented in nanomoles of $\mathrm{NADH}$ per minute per milligram of protein. CS activity in 
$0.1 \mathrm{mg} / \mathrm{ml}$ mitochondria was measured by the reduction of DTNB as described previously (Shepherd and Garland, 1969).

Mitochondrial superoxide detection in cells. Mitochondrial superoxide detection in cells was performed in primary neurons cultured for $3 \mathrm{~d}$ in the glass-bottom poly-D-lysine-coated microwell dishes (Ø35/10 mm) (MatTek). Cells were seeded at a density of $5 \times 10^{2}$. To detect mitochondrial superoxide production, cells were washed with HBSS and incubated with MitoSOX Red $(0.2 \mu \mathrm{m}$ in HBSS, $15 \mathrm{~min}$; Invitrogen) followed by incubation with Hoechst $33342(0.2 \mu \mathrm{M}$ in HBSS, $5 \mathrm{~min}$; Invitrogen). MitoSOX Red selectively detects superoxide in the mitochondrial matrix (Kirkland et al., 2007; Robinson et al., 2008). The concentration of MitoSOX $(0.2 \mu \mathrm{M})$ was selected to avoid cellular toxicity and nonspecific nuclear fluorescence (Simonyan and Skulachev, 1998; Robinson et al., 2008). After incubation with fluoroprobes, cells were washed with HBSS and examined under inverted microscope (Axio Observer Z1; Zeiss). MitoSOX fluorescence was detected using filter (43HE DS-Red; excitation, 563; emission, $581 \mathrm{~nm}$ ) and Hoechst with the filter (Ste 02; excitation, 365; emission, 420). Images were examined and captured at $37^{\circ} \mathrm{C}$ using $63 \times$ oil objective. The parameters for image capture, fluorescent light intensity and exposure time $(500 \mathrm{~ms})$, were set at the initial imaging of $\mathrm{Clq}^{-1-}$ naive cells and then kept identical for all other studied samples during each experiment. To minimize photooxidation of MitoSOX, the microscopy time for a field selection and adjustment of focus were kept constant $(10 \mathrm{~s})$ for all images. For semiquantification of MitoSOX fluorescence, five nonadjacent images (259,840 pixels) per well from each experimental condition were collected and the number of cells (Hoechstpositive nuclei) in each image were counted. The mean value per well represented a single observation $(n=1)$. Two to four wells per each experimental group were analyzed in each experiment. Data from a total of three separate experiments (three separate neuronal preparations) were analyzed. In neurons after 2-4 h of OGD, the exposure to MitoSOX caused significant cellular mortality and intensive nonspecific nuclear MitoSOX fluorescence. Therefore, the duration of OGD exposure was reduced to $30 \mathrm{~min}$. All images were obtained at $60-70 \mathrm{~min}$ of reperfusion. MitoSOX fluorescence was quantified using ImageJ analysis software and expressed in pixels normalized per cell count.

Electron microscopy. Electron microscopy of brains in WT mice was performed to examine intraneuronal presence and localization of $\mathrm{Clq}$ before $(n=2)$ and at $12 \mathrm{~h}$ after $\mathrm{HI}$ insult $(n=2)$. Briefly, brains were fixed ( $4 \%$ paraformaldehyde plus $0.1 \%$ glutaraldehyde). Then, samples (small pieces of neocortex) were embedded in LR-white medium (Electron Microscopy Laboratory). Ultrathin sections were blocked in $10 \%$ donkey serum and incubated with goat/human anti-C1q polyclonal antibody (1:200; Biomeda) followed by incubation with secondary IgG donkey anti-goat antibody conjugated with donkey anti-mouse antibody conjugated with colloidal gold (12 nm particle; 1:40; Jackson ImmunoResearch Laboratories). Sections were counterstained with uranyl acetate and examined under electron microscope (JEOL 100S; Jackson ImmunoResearch Laboratories). To quantify C1q accumulation in neuronal mitochondria, the C1q-immunogold particles present in the mitochondrial projection were counted in 49 organelles in naive and 57 organelles in HI mice and expressed as mean count of particles per mitochondrion.
Extent of oxidative brain damage. The extent of oxidative brain damage was analyzed by visual detection and semiquantification of immunopositivity of markers for lipid peroxidation [4-hydroxy-nonenal (4HNE)] and protein peroxinitrolysation [3-nitrotyrosine (3NT)]. In brief, at 4 and $24 \mathrm{~h}$ of reperfusion, brains were harvested from randomly selected $\mathrm{Clq}^{-1-}$ and age- and strain-matched WT mice, fixed in $4 \%$ paraformaldehyde, and soaked in $30 \%$ sucrose overnight. The 20 $\mu \mathrm{m}$-thick coronal sections were blocked (10\% donkey serum) and incubated with rabbit polyclonal anti-4-HNE (1:500) and anti-3NT antibodies (1:100) as described previously (Zhu et al., 2007). Samples were examined using Bio-Rad 2000 confocal laser-scanning device attached to a Nikon E800 microscope. The 4-HNE and 3-NT immunoreactivity was analyzed by the count of immunopositive neurons in five nonadjacent fields $(40 \times)$ of injured cortex at three different bregma levels $(-1.0,0,+1.0 \mathrm{~mm})$. Thus, 15 areas of cortex were analyzed for each mouse and mean value of cell count per square millimeter per mouse was used for statistical analysis. Only those WT and $\mathrm{Clq}^{-1-}$ mice that developed signs of neuronal injury (diminished expression of MAP2) were used for data analysis.

Statistical analysis. All data were expressed as mean \pm SEM. One-way ANOVA or ANOVA for repeated-measures or $t$ test, when appropriate, with Fisher's post hoc analysis were used to compare the extent of cerebral injury, cellular viability, the degree of $\mathrm{C}$ component deposition, and oxidative stress among three or two groups. Data were considered statistically significant if $p<0.05$. 


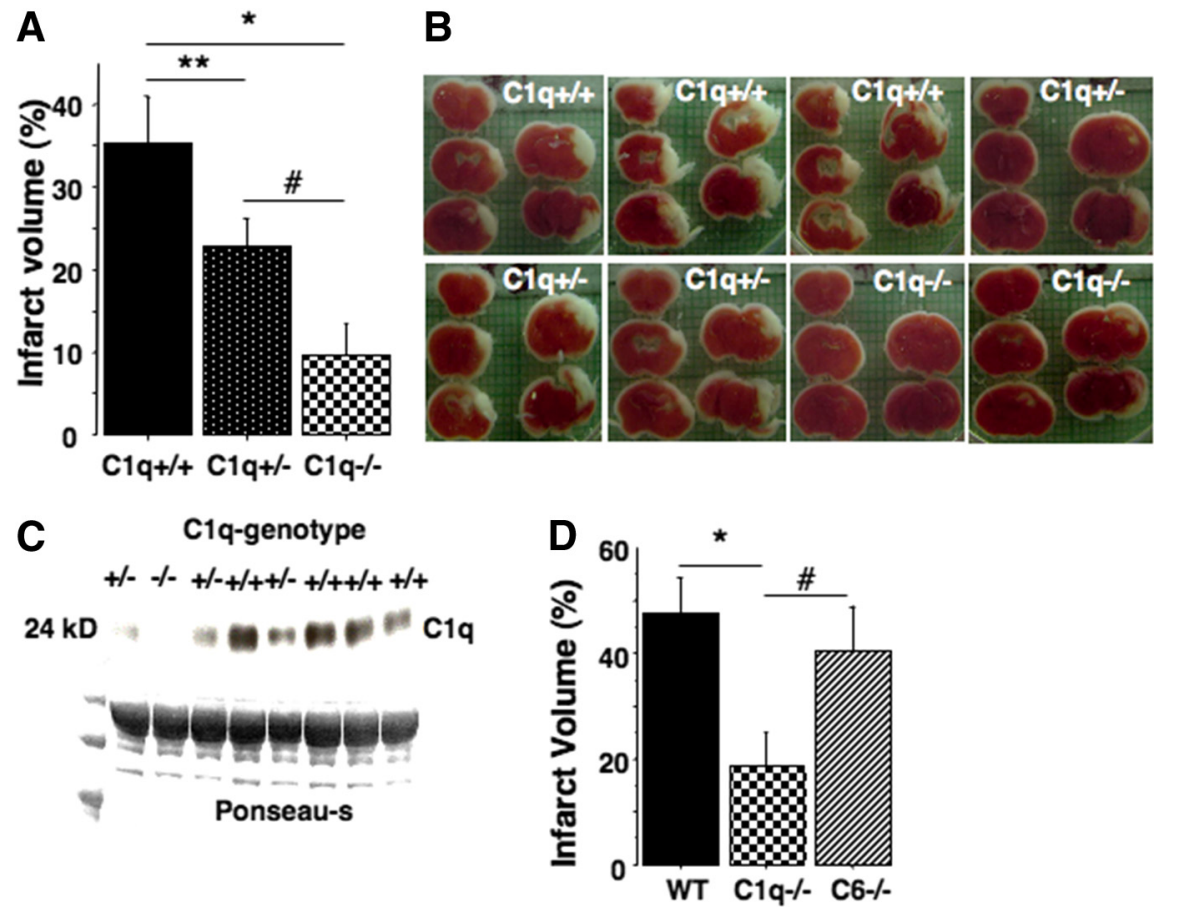

Figure 2. $\quad \boldsymbol{A}, \boldsymbol{B}$, Cerebral infarct volumes in $\mathrm{C} \mathrm{q}^{+/+}$(black bar; $\left.n=15\right), \mathrm{C}^{+1-}$ (dotted black bar; $\left.n=29\right)$, and $^{+1} 1 \mathrm{q}^{-1-}$ (checkered bar; $n=21$ ) HI mice $(\boldsymbol{A})$, and TTC-stained coronal brain sections from a single litter of $\mathrm{C}_{\mathrm{q}}{ }^{+/-}$mating progenies subjected to hypoxia-ischemia $(\boldsymbol{B}) .{ }^{*} p=0.0003 ;{ }^{* *} p=0.04 ;{ }^{*} p=0.02$. $\boldsymbol{C}$, Western blot analysis for cerebral $\mathrm{C} 1 \mathrm{q}$ content in a litter of $\mathrm{C}_{\mathrm{q}}{ }^{+/-}$mating progenies subjected to hypoxia-ischemia. $\boldsymbol{D}$, Cerebral infarct volumes in WT (black bar; $\left.n=9\right),\left(1 q^{-1-}\right.$ (checkered bar; $n=10)$, and $\mathrm{C}^{-1-}$ (striped bar; $\left.n=11\right) \mathrm{HI}$ mice. ${ }^{*} p=0.01 ;{ }^{*} p=0.03$. All data are mean \pm SEM.
$\mathrm{Clq}^{+/+}$littermates (Fig. $\left.2 A, B\right) \cdot \mathrm{Clq}^{+/-}$ littermates also demonstrated significantly $(p=0.04)$ attenuated extent of brain damage compared with their $\mathrm{Clq}^{+/+}$littermates. The distribution of cerebral infarct volumes among $\mathrm{Clq}^{-/-}$, $\mathrm{Clq}^{+/-}$, and $\mathrm{Clq}^{+/+}$littermates was associated with both $\mathrm{Clq}$-protein content in their brains and genotype (Fig. 2B,C). Although mice pretreated with sCD59 exhibited significantly decreased deposition of C9 in the injured hemisphere, their cerebral infarct volumes were similar $(42 \pm 7.4 \% ; n=6)$ to the vehicle-treated HI littermates (40 \pm $4.87 \% ; n=6)$. When $\mathrm{Clq}^{-/-}$, WT, and C6-deficient mice were exposed to hypoxia-ischemia of an identical severity, only $\mathrm{Clq}^{-/-}$mice demonstrated significant neuroprotection (Fig. 2D). In contrast, $\mathrm{C}^{-1-}$ mice demonstrated brain injury to a similar extent as their WT counterparts (Fig. 2D). The serum obtained from these $\mathrm{C}^{-1-} \mathrm{HI}$ mice failed to restore MAC-hemolytic activity $\left[5.09 \pm 1.6 \%\left(\mathrm{C6}^{-1-} ; n=4\right)\right.$ vs $63 \pm$ 2.2\% (WT; $n=4$ ) hemolysis; $p<$ 0.0001] of the C6-deficient human serum, providing a functional confirmation for C6 deficiency.

\section{Results}

Complement is activated in the ischemic brain

At $24 \mathrm{~h}$ after hypoxia-ischemia, WT mice demonstrated deposition of $\mathrm{C} 3$-split products $(\mathrm{C} 3 \mathrm{~b} / \mathrm{iC} 3 \mathrm{~b} / \mathrm{C} 3 \mathrm{c})$ and $\mathrm{C} 9$ only in the ischemic (ipsilateral) hemisphere (Fig. $1 A, B, E, F, H, I$ ). Western blot analysis revealed markedly increased $\mathrm{C} 3 \mathrm{~d}$ content in the ipsilateral versus contralateral hemispheres (Fig. 1D). The C-specific immunosignals were detectable in the injured areas of brain defined by the remnant presence or the absence of immunoreactivity for MAP2 (Fig. $1 B, F$ ).

\section{Genetic ablation of $\mathrm{Clq}$ or pretreatment with sCD59 attenuates terminal $\mathrm{C}$ activation}

At $24 \mathrm{~h}$ of reperfusion, $\mathrm{Clq}^{-/-}$mice exhibited attenuated deposition and expression of $\mathrm{C} 3$-split products and $\mathrm{C} 9$ in their injured brains compared with $\mathrm{Clq}^{+/+}$littermates (Fig. $1 B, C, F, G$ ). Semiquantitative analysis revealed significantly $(p<0.03)$ smaller size of the areas immunopositive for C3-split products $\left(7.36 \pm 1.87 \times 10^{3}\right.$ pixels; $\left.n=4\right)$ and C9 $\left(4.8 \pm 1.3 \times 10^{3}\right.$ pixels; $n=4)$ in $\mathrm{Clq}^{-/-}$mice compared with their $\mathrm{Clq}^{+/+}$littermates $\left(17 \pm 3.6 \times 10^{3}\right.$ and $14.2 \pm 2.7 \times 10^{3}$ pixels, respectively; $\left.n=4\right)$. Similarly, Western blot analysis also showed significantly $(p<$ 0.03 ) decreased $\mathrm{C} 3 \mathrm{~d} / \beta$-actin ratio in the ischemic brains in $\mathrm{Clq}^{-1-}$ mice $(n=4)$ compared with $\mathrm{Clq}^{+/+}$mice $(n=3)$. Mice pretreated with sCD59 compared with their vehicle-treated littermates exhibited significantly $(p=0.01)$ reduced deposition of C9 $\left(5.2 \pm 1.9 \times 10^{3}\right.$ vs $31.8 \pm 11 \times 10^{3}$ pixels; $\left.n=4\right)$ in the HI-injured cortex and hippocampus (Fig. $1 \mathrm{H}-\mathrm{J}$ ).

Only $\mathrm{Clq}^{-1-}$ mice were protected against hypoxia-ischemia Analysis of the brain damage revealed a significant $(p=0.0003)$ decrease of infarct volume in $\mathrm{Clq}^{-1-}$ mice compared with their
C1q accumulates in neuronal cytosol and mitochondria after hypoxia-ischemia

Electron microscopy revealed that, in naive WT mice, neurons constitutively express $\mathrm{Clq}$ in the cytosol and mitochondria (0.81 \pm 0.42 immunogold particles per organelle) (Fig. 3A). However, in response to hypoxia-ischemia and $12 \mathrm{~h}$ of reperfusion, there was a markedly increased presence of $\mathrm{Clq}$ in neuronal cytosol associated with significantly increased $(4.23 \pm 1.82 \mathrm{Clq}$ immunogold particles per organelle; $p<0.0001)$ accumulation of $\mathrm{Clq}$ in mitochondria (Fig. $3 A, B$ ). Of note, $8.76 \%$ of mitochondria in HI neurons exhibited very dense (the distance between particles, $\sim 12 \mathrm{~nm}$ ) accumulation of C1q in the matrix (Fig. $3 B, C)$. Western blot analysis also revealed an increasing presence of $\mathrm{C} 1 \mathrm{q}$ in the ipsilateral hemisphere at 3.5 and $7 \mathrm{~h}$ of reperfusion, compared with naive mice (supplemental Fig. $1 A$, available at www.jneurosci.org as supplemental material).

C1q ablation limits mitochondrial ROS emission and extent of oxidative brain injury only in neonatal mice Brain mitochondria isolated from $\mathrm{Clq}^{-1-}$ mice exhibited a significantly decreased rate of ROS emission compared with their $\mathrm{Clq}^{+/+}$littermates at all time points, before hypoxia-ischemia (naive mice), at 0, 30-60 $\mathrm{min}$, and 4-6 h after hypoxia-ischemia (Fig. 3D-G). Importantly, in WT HI mice at 0 min of reperfusion, the rate of mitochondrial ROS emission in the brain did not differ from that in their naive littermates (Fig. 3E). However, once reperfusion was established, WT mice demonstrated a robust acceleration in mitochondrial ROS emission rate compared with naive and non-reperfused $\mathrm{HI}$ littermates (Fig. $3 E$ ). In contrast, $\mathrm{Clq}^{-1-} \mathrm{HI}$ mice exhibited a significantly lower rate of ROS release at 30-60 min of reperfusion compared with WT counterparts, although it was significantly increased compared with that 
at $0 \mathrm{~min}$ of reperfusion (Fig. $3 E$ ). The $\mathrm{Clq}^{-1-}$ genotype-associated inhibition in ROS emission rate was detected before and after inhibition of the C-I with rotenone (Rot) and inhibition of the C-III with antimycin A (AntA) (Fig. $3 F, G$ ). Remarkably, at $4-6 \mathrm{~h}$ of reperfusion, the rate of ROS emission in WT HI mice was diminished compared with that at 30-60 min of reperfusion. At the same time, $\mathrm{Clq}^{-1-}$ mice mitochondria continued to generate ROS at a rate comparable with that of their naive littermates (Fig. 3E). Of note, no difference in mitochondrial membrane potential was found between $\mathrm{Clq}^{-/-}$and $\mathrm{Clq}^{+/+}$mice assessed at 0 (data not shown) and 30 min of reperfusion, the time point when ROS emission rate differed the most between two genotypes (supplemental Fig. $1 C$, available at www.jneurosci.org as supplemental material). At 4 and $24 \mathrm{~h}$ of reperfusion, staining of brains for markers of lipid and protein oxidative damage (4HNE and $3 \mathrm{NT}$ ) revealed significantly attenuated signs of oxidative stress in $\mathrm{Clq}^{-1-}$ mice compared with WT mice (Fig. 4A-G). The signs of oxidative brain damage were detectable at $4 \mathrm{~h}$ of reperfusion with additional magnification by $24 \mathrm{~h}$ of reperfusion in mice of both genotypes. This was associated with a gradual loss of the MAP2 immunopositivity, indicating a propagation of cellular damage and death (Fig. 4A-E).

Surprisingly, brain mitochondria isolated from naive adult (10-week-old) $\mathrm{Clq}^{-1-}$ mice demonstrated the same rate of ROS emission as mitochondria from C1 $\mathrm{q}^{+/+}$mice (supplemental Fig. $1 D-F$, available at www.jneurosci.org as supplemental material). This coincided with the absence of neuroprotective effect of $\mathrm{C} 1 \mathrm{q}$ gene deletion against $\mathrm{HI}$ injury in mature mice (supplemental Fig. 1G,H, available at www.jneurosci.org as supplemental material).

\section{C1q deletion attenuates post-HI}

inhibition of mitochondrial respiration At 0 min of reperfusion, mitochondria isolated from the ipsilateral hemisphere of neonatal WT mice demonstrated significant $(p=0.0001)$ inhibition of phosphorylating and uncoupled respiration along with poorer RCR compared with their naive counterparts (Fig. $5 A, B, D$ ). No significant changes in the resting (state 4) respiration rates were detected in $\mathrm{HI}$ mice of both genotypes (Fig. $5 C$ ). Importantly, at $0 \mathrm{~min}$ of reperfusion, cerebral mitochondria from $\mathrm{Clq}^{-1-}$ mice compared with their WT counterparts exhibited minimally inhibited respiratory chain activity, as defined by ADP-phosphorylating and uncoupled respiration rates (Fig. $5 A, B)$. This was associated with spared C-I activity in $\mathrm{Clq}^{-1-}$
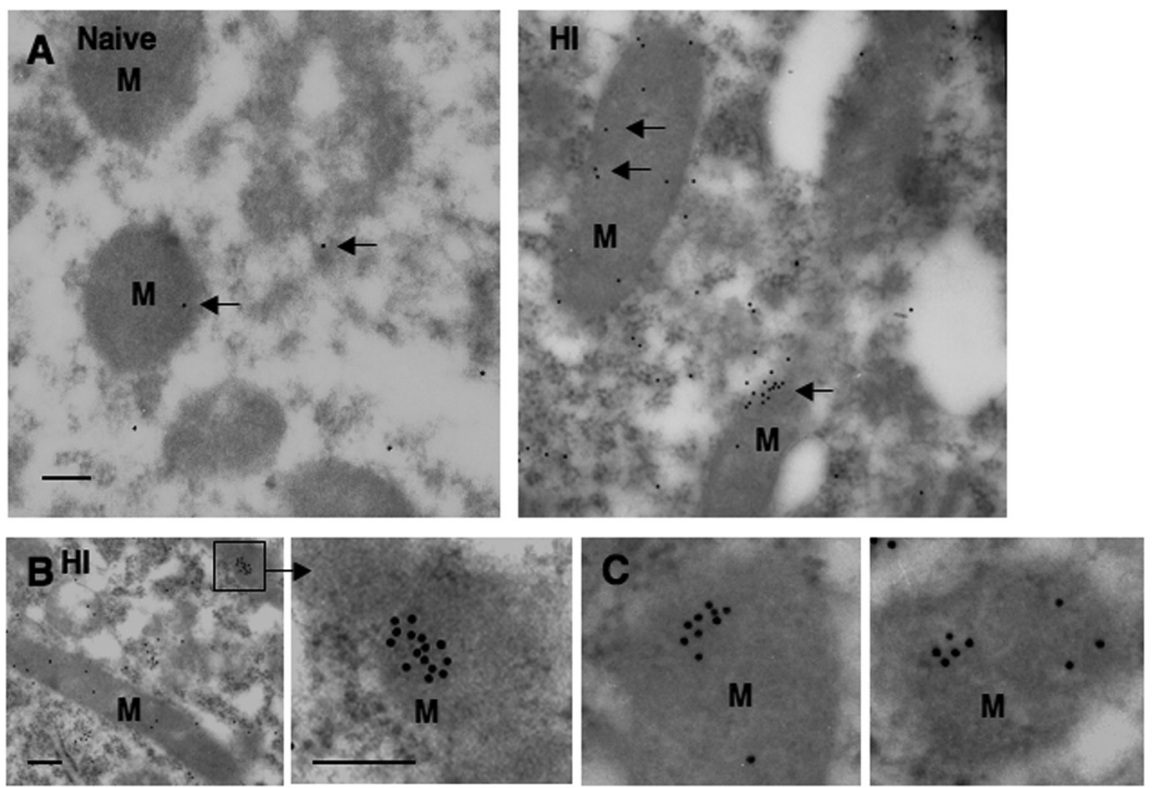

D

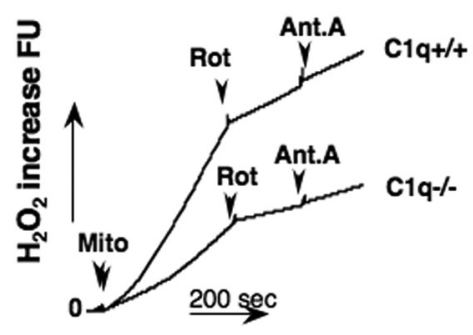

$\mathbf{F}$

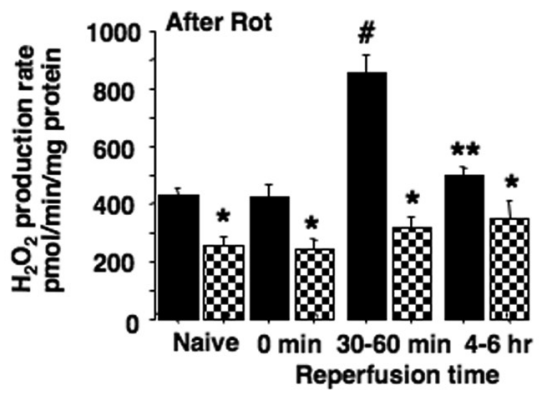

E
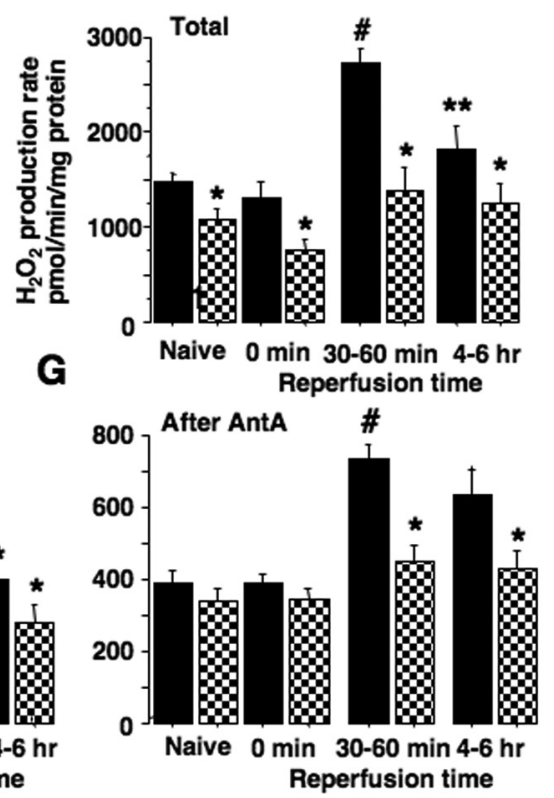

Figure 3. $A$, Electron microscopy of neurons immunostained for $\mathrm{C} 1 \mathrm{q}$ with antibodies conjugated with $12 \mathrm{~nm}$ immunogold (arrows) in naive and $\mathrm{HI}$ mice at $12 \mathrm{~h}$ of reperfusion $(\boldsymbol{A})$. In $\boldsymbol{B}$, the arrow indicates inset of magnified areas in this and other $(\boldsymbol{C})$ neurons with characteristic dense accumulation of $\mathrm{C} 1 \mathrm{q}$ in mitochondria. Scale bars, $100 \mathrm{~nm}$. M, Mitochondrion. $\boldsymbol{D}$, Representative recording of changes in $\mathrm{H}_{2} \mathrm{O}$-specific fluorescence measured in cerebral mitochondria isolated from $\mathrm{C}_{1 \mathrm{q}}{ }^{+/+}$and $\mathrm{Clq}^{-1-}$ mice at 30 min of reperfusion. The arrows indicate supplementation of mitochondria (Mito), rotenone (Rot), and antimycin A (Ant.A). $\boldsymbol{E}-\mathbf{G}, \mathrm{H}_{2} \mathrm{O}_{2}$ generation rate in mitochondria isolated from $\mathrm{C} \mathrm{q}^{+/+}$(black bar) and $\mathrm{C}^{-1-} \mathrm{q}^{-1}$ (checkered bar) at different time points after $\mathrm{HI}$ insult. Naive mice $(n=11$ and 8$)$ at $0 \mathrm{~min}(n=4$ in both groups), at $30-60 \mathrm{~min}(n=8$ and 5$)$, and at $4-6 \mathrm{~h}(n=$ 7 and 5 ) of reperfusion. $\boldsymbol{E}$, Total rate. $\boldsymbol{F}$ is the rate after rotenone supplementation, and $\boldsymbol{G}$ is the rate after antimycin-A supplementation. ${ }^{*} p<0.05$ compared with the corresponding WT mice; ${ }^{*} p \leq 0.01$ compared with naive and that at 0 min of reperfusion; ${ }^{* *} p \leq 0.02$ compared with that measured at 30-60 min of reperfusion in WT mice. Error bars indicate SEM.

mice, but not in WT mice in which hypoxia-ischemia caused significant inhibition of C-I (Fig. 5E). At 30-60 min of reperfusion, the rate of mitochondrial $\mathrm{O}_{2}$ consumption during state 3 respiration was well coupled and fully restored in both groups of mice and did not differ from their naive counterparts (Fig. $5 A, B, D)$. In WT HI mice, this fully restored activity of the mitochondrial respiratory chain was paralleled with the peak in post-HI ROS emission rate detected at 30-60 min of reperfusion 

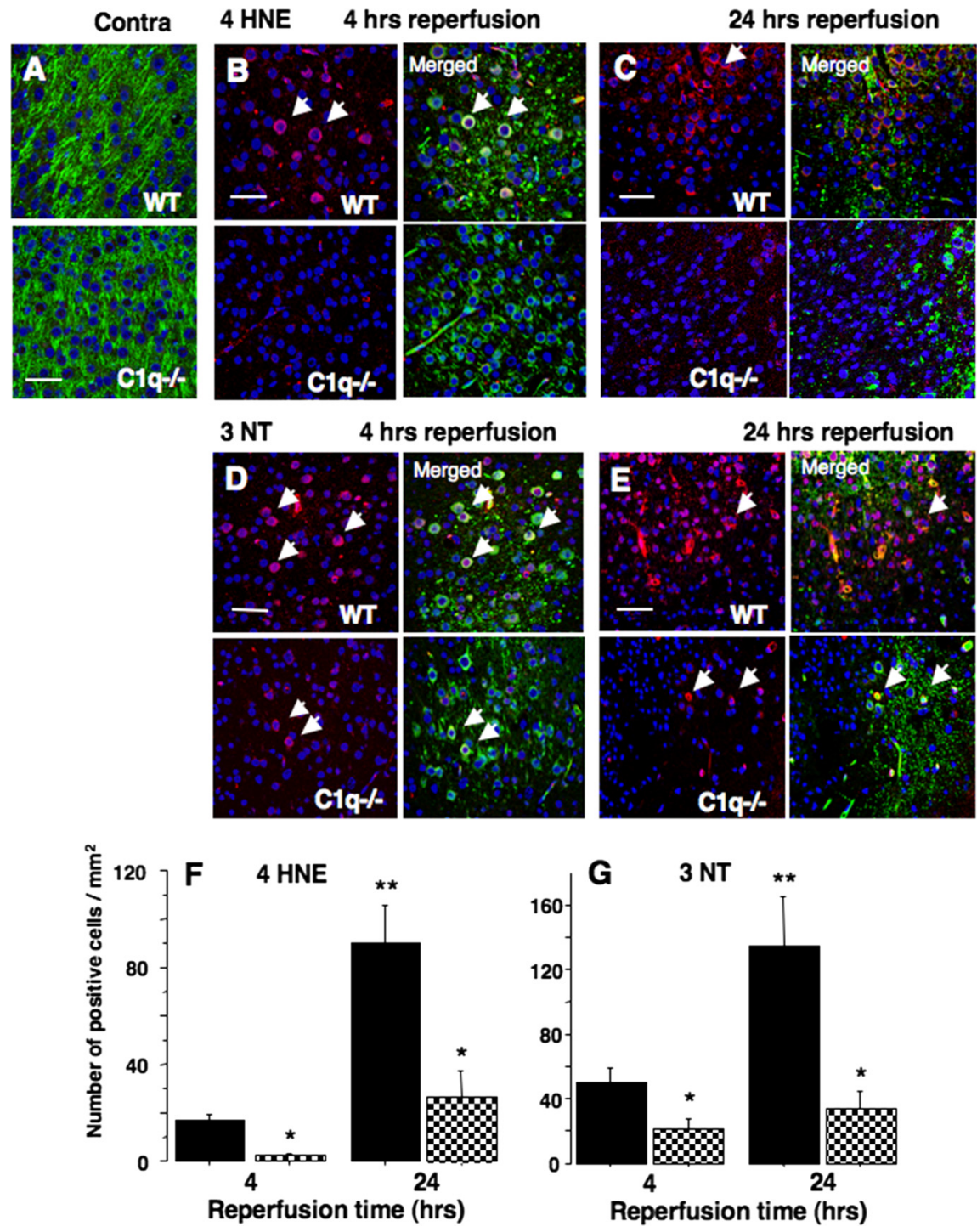

Figure 4. Confocal microscopy of the cortex immunostained for $4 \mathrm{HNE}$ (pink) in naive $(\boldsymbol{A})$ and $\mathrm{HI}$ mice at $4 \mathrm{~h}(\boldsymbol{B})$ and $24 \mathrm{~h}(\boldsymbol{C})$ of reperfusion. $\boldsymbol{D}, \boldsymbol{E}$, The cortex immunostained for $3 \mathrm{NT}$ (pink) at $4 \mathrm{~h}(\boldsymbol{D})$ and $24 \mathrm{~h}(\boldsymbol{E})$ of reperfusion. The genotypes of mice are indicated. Blue is Nissl, and green is MAP2. Scale bars, $50 \mu \mathrm{m}$. The arrows indicate positive 4HNE and 3NT cells. F, G, The number of positive cells in WT (black bar; $n=5$ ) and $1 \mathrm{Cq}^{-1-}$ (checkered bar; $n=4$ ) mice. ${ }^{*} p \leq 0.03$ compared with WT counterparts $(t$ test $) ;{ }^{* *} p<0.02$ compared with that at $4 \mathrm{~h}$ of reperfusion (repeated-measures ANOVA). Error bars indicate SEM.

(Fig. 3E). However, at $4-6$ h of reperfusion, mitochondrial phosphorylating and uncoupled respiration in WT HI mice declined significantly ( $p=0.01)$ compared with that in WT naive mice or WT HI mice studied at 30-60 min of reperfusion, and compared with $\mathrm{Clq}^{-1-} \mathrm{HI}$ mice (Fig. $5 A, B$ ). At the same time point of reperfusion, the RCR in WT HI mice was also significantly decreased compared with their naive littermates (Fig. 5D). In contrast, in $\mathrm{Clq}^{-/-} \mathrm{HI}$ mice, mitochondrial respiration rates (state 3 and DNP accelerated) assessed at the same time point did not differ from that in naive $\mathrm{Clq}^{-1-}$ mice (Fig. $5 A, B$ ).

Exposure to C1q increased mitochondrial superoxide only in cultured neurons

When $\mathrm{Clq}^{-1-}$ cortical neurons were exposed to hC1q for $90 \mathrm{~min}$ and labeled with MitoSOX, an elevation $(p=0.06)$ of superoxide-specific signal was detected (Fig. $5 F$ ). This effect was absent after exposure to a heat-inactivated hClq (Fig. $5 F$ ). Electron microscopy of $\mathrm{Clq}^{-/-}$neurons revealed an appearance of
$24 \mathrm{hrs}$ reperfusion

hClq immunosignal in the neuronal cytosol and mitochondria after 90 min incubation with hClq (Fig. 5G,H). An incubation of hClq with isolated $\mathrm{Clq}^{-/-}$mitochondria resulted in hC1q-mitochondria interaction (supplemental Fig. $1 B$, available at www.jneurosci.org as supplemental material). However, this interaction did not affect mitochondrial ROS emission rate (data not shown).

$\mathrm{Clq}^{-/-}$neurons are protected against OGD and exposure to hC1q abrogates this protection

Cortical $\mathrm{Clq}^{-1-}$ neurons demonstrated a dramatic ( $p=0.0007)$ protection against OGD challenge compared with their WT counterparts (Fig. 6A). However, when OGD-stressed $\mathrm{Clq}^{-/-}$cells were "reperfused" in the presence of increasing concentrations of hC1q, neuronal viability decreased in the hClq dose-dependent manner (Fig. 6A). No change in OGDinduced mortality was detected after reperfusion of $\mathrm{Clq}^{-/-}$neurons with heat-inactivated hC1q. Importantly, the deleterious effect of hClq on cellular survival was fully abrogated in the presence of the ROS scavenger, Trolox (Fig. 6A). The OGD and $60 \mathrm{~min}$ of reperfusion significantly increased mitochondrial superoxide-specific fluorosignal only in WT neurons (Fig. 6B, C). In C1q ${ }^{-1-}$ OGD-stressed cells, the MitoSOX fluorescence was significantly reduced compared with that in WT OGD cells (Fig. 6B,C). The exposure to hC1q during $60 \mathrm{~min}$ of reperfusion further increased ROS signal in $\mathrm{Clq}^{-1-}$ cells, and heat inactivation of $\mathrm{hClq}$ prevented this effect (Fig. 6C).

\section{Discussion}

Complement is activated in the ischemic brain after hypoxia-ischemia in immature rodents and in human infants (Cowell et al., 2003; Schultz et al., 2005). We also found markers for Cactivation (C3-split products and C9) only in the post-HI brain. In $\mathrm{Clq}^{-/-}$mice, signs of $\mathrm{C}$ activation and deposition of the terminal $\mathrm{C}$ complex were significantly decreased, the event associated with neuroprotection against hypoxia-ischemia. This suggests that the neuroprotection in $\mathrm{Clq}^{-1-}$ mice is attributable to a limited $\mathrm{C}$ activation and assembly of the terminal $\mathrm{C}$ complex. However, neither genetic (C6 ${ }^{-1-}$ mice) nor pharmacological (pretreatment with sCD59) inhibition of the terminal $\mathrm{C}$ complex assembly resulted in protection against hypoxia-ischemia. This implies that terminal $\mathrm{C}$ complex does not contribute to the HI injury in the developing brain. C1q-mediated $\mathrm{C}$ activation pathway generates proinflammatory mediators, C3a and C5a, implicated in the pathogenesis of focal ischemic brain injury (Van Beek et al., 2000; Mocco et al., 2006). The neuroinflammatory response develops within hours and days after hypoxia-ischemia (Ferriero, 2004). In our experiments, $\mathrm{Clq}^{-1-}$ mice exhibited signs of neuroprotection (significantly better preserved mitochondrial phosphorylating respiration 
and C-I activity) even before the reperfusion, when neuroinflammation cannot be considered. Therefore, it is unlikely that attenuated complement-mediated neuroinflammation accounts for neuroprotection in $\mathrm{Clq}^{-/-}$mice.

In C1q-sufficient mice, hypoxia-ischemia and reperfusion were associated with robust accumulation of $\mathrm{Clq}$ in the neuronal cytosol and mitochondria. This is consistent with a dramatic overexpression of $\mathrm{Clq}$ in the brain after global ischemia (Schäfer et al., 2000) and in neuron-like PC12 cells on hypoxic stress (Tohgi et al., 2000). Although this postischemic upregulation and accumulation of $\mathrm{Clq}$ in the brain can be the initial sign of classical $\mathrm{C}$ activation pathway, there is another molecular effect associated with neuronal presence of $\mathrm{Clq}$, accelerated release of ROS from mitochondria. In the absence of C1q, brain mitochondria generated significantly less ROS compared with C1qsufficient littermates. $\mathrm{Clq}^{-1-}$ genotype was also associated with significantly better preservation of the mitochondrial phosphorylating and uncoupled respiration and C-I activity at the end of $\mathrm{HI}$ insult. This suggests that the absence of $\mathrm{Clq}$ protects mitochondrial respiratory chain against inhibition by hypoxia-ischemia. Postischemic inhibition of mitochondrial C-I was suggested as a molecular mechanism responsible for excessive generation of ROS from mitochondrial respiratory chain during reperfusion (Chen et al., 2008). An accelerated ROS emission from cerebral mitochondria in $\mathrm{Clq}^{+/+} \mathrm{HI}$ mice could be explained by a greater C-I inhibition compared with $\mathrm{Clq}^{-/-} \mathrm{HI}$ mice. However, mitochondria obtained from naive $\mathrm{Clq}^{+/+}$and $\mathrm{Clq}^{-/-}$mice with unaltered C-I activity also exhibited a markedly different rate in ROS emission, pointing to a C-I-independent mechanism for $\mathrm{C1q}$ regulation of mitochondrial ROS release. It has been proposed that accelerated mitochondrial ROS emission after global brain ischemia is responsible for inactivation of respiratory chain complexes, including C-I (Racay et al., 2009). Therefore, the relative resistance of C-I toward an inhibiting effect of hypoxia-ischemia in $\mathrm{Clq}^{-/-}$HI mice could be secondary to a limited acceleration in ROS emission during $\mathrm{HI}$ insult so that ROS levels in the mitochondrial matrix do not reach a threshold to cause C-I dysfunction. Neuronal mitochondria were shown to respond with a burst of ROS release within minutes of initiation of OGD. By the end of OGD challenge, mitochondrial emission of ROS declined secondary to collapsed $\Delta \Psi \mathrm{m}$ (Abramov et al., 2007). Importantly, a difference in $\Delta \Psi \mathrm{m}$, a well established regulator of mitochondrial ROS production
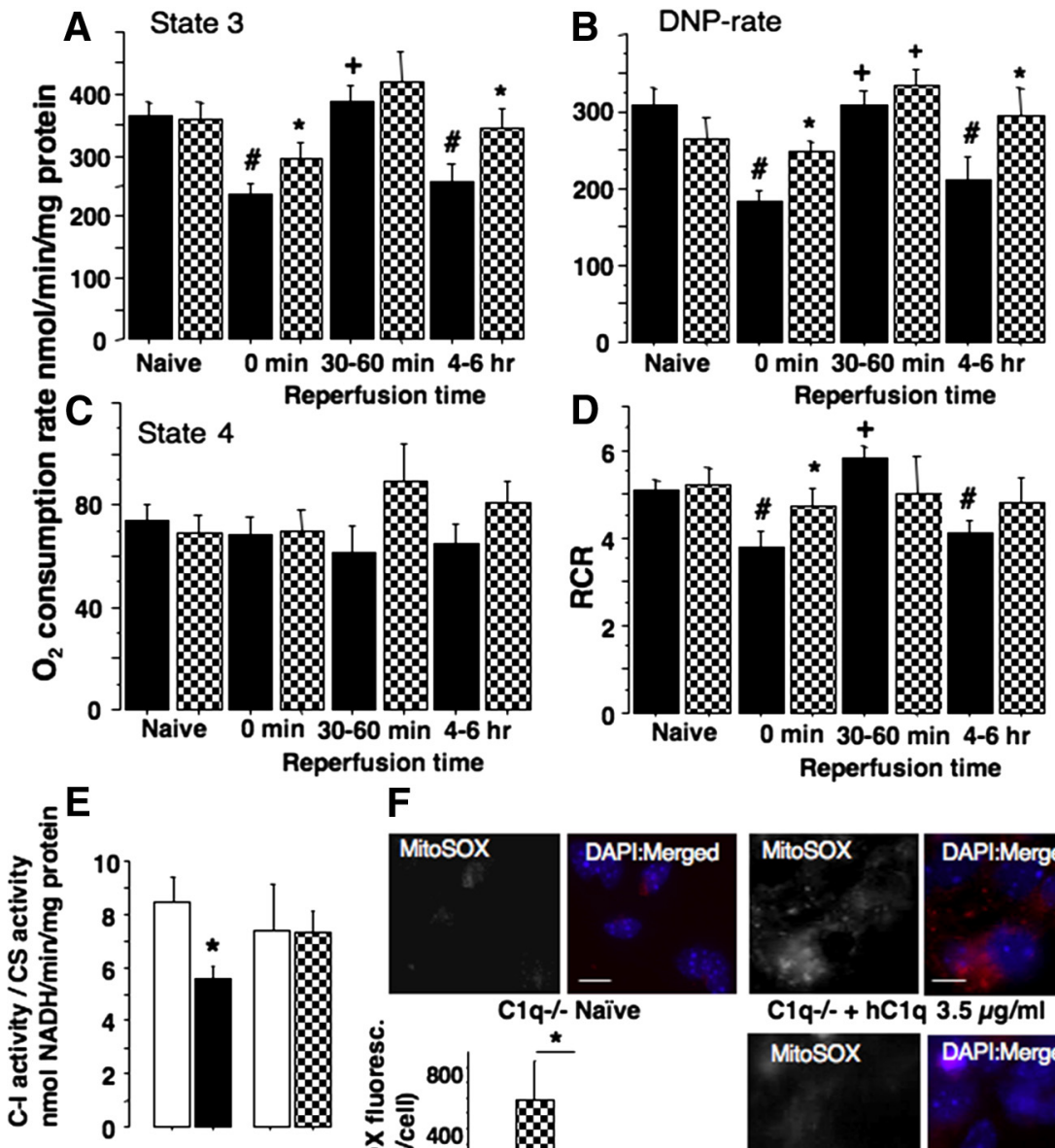

F

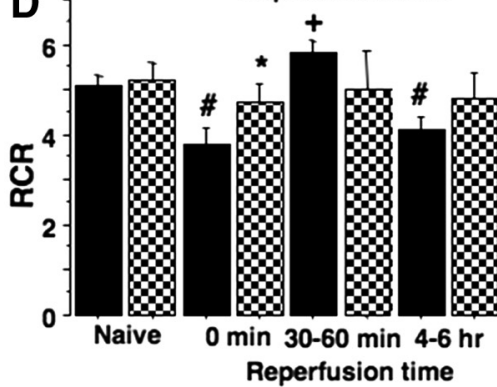

G

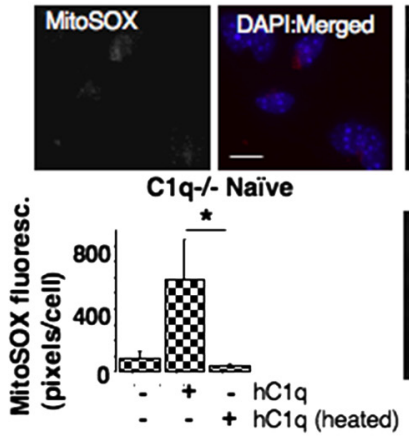

H

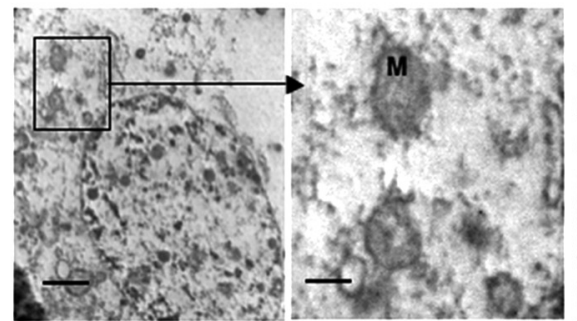

C1q-/-neuron

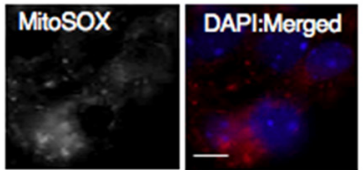

$\mathrm{C} 1 \mathrm{q}-1-+\mathrm{hC1q} 3.5 \mu \mathrm{g} / \mathrm{ml}$

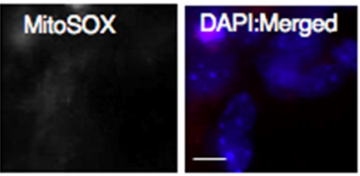

C1q- -+ hC1q heated
Figure 5. $A-D, O_{2}$ consumption rates and RCR in cerebral mitochondria isolated from WT (black bar) and $\mathrm{Clq}^{-/-}$(checkered bar) in naive ( $n=14$ and 11) mice and $\mathrm{HI}$ mice at different time points of reperfusion: at $0 \mathrm{~min}(n=14$ and 12), at 30 $-60 \mathrm{~min}$ ( $n=4$ and 4$)$, and at $4-6 \mathrm{~h}(n=6$ and 6$)$. A, State 3. B, 2,4-DNP-accelerated. C, State 4 respiration rates. D, RCR. ${ }^{*} p<0.05$ compared with WT counterparts; ${ }^{\#} p \leq 0.03$ compared with naive WT mice; ${ }^{+} p \leq 0.05$ compared with that at 0 min of reperfusion. $\boldsymbol{E}$, Enzymatic activity of the $\left(-l\right.$ in WT and $\left(1 q^{-1-}\right.$ naive (white bars; $n=9$ and 5$)$ and in WT HI mice (black bar; $n=9$ ) and $\mathrm{C} \mathrm{q}^{-1-} \mathrm{HI}$ mice (checkered bar; $\left.n=5\right) .{ }^{*} p=0.009$ compared with WT naives. $\boldsymbol{F}$, Images of live $\mathrm{C} \mathrm{q}^{-1-}$ cortical neurons costained with MitoSOX Red (red) and Hoechst (blue): before (naive) and after exposure to active or heat-inactivated hC $1 \mathrm{q}$ (3.5 $\mu \mathrm{g} / \mathrm{ml}$ ) for $90 \mathrm{~min}$. Scale bars, $10 \mu \mathrm{m}$. Semiquantitative analysis of changes in MitoSOX fluorescence in response to coincubation with active or heat-inactivated $\mathrm{hC}\left(\mathrm{q}\left(n=10 ;{ }^{*} p=0.02\right) . \mathbf{G}, \boldsymbol{H}\right.$, Electron microscopy of cultured $\mathrm{Clq}^{-1-}$ neurons immunostained for $(1 \mathrm{q}$ protein (immunogold, $12 \mathrm{~nm}$ ) before $(\boldsymbol{G})$ and after $(\boldsymbol{H}) 90$ min exposure to $\mathrm{hC}(\mathrm{q}(3.5 \mu \mathrm{g} / \mathrm{ml})$. The arrows indicate immunogold particles in the neuronal cytosol and mitochondria (M). Scale bars, 1 and $5 \mu \mathrm{m}$. Error bars indicate SEM.

rate (Starkov and Fiskum, 2003), cannot account for the difference in mitochondrial ROS emission in $\mathrm{Clq}^{+/+}$versus $\mathrm{Clq}^{-/-}$ mice, as $\Delta \Psi \mathrm{m}$ did not differ between mice of these genotypes. We also found no difference in the mitochondrial total GSH content or the presence of GPx, GR, and MnSOD in mitochondria isolated from $\mathrm{Clq}^{-/-}$and $\mathrm{Clq}^{+/+}$naive or $\mathrm{HI}$ mice (supplemental 


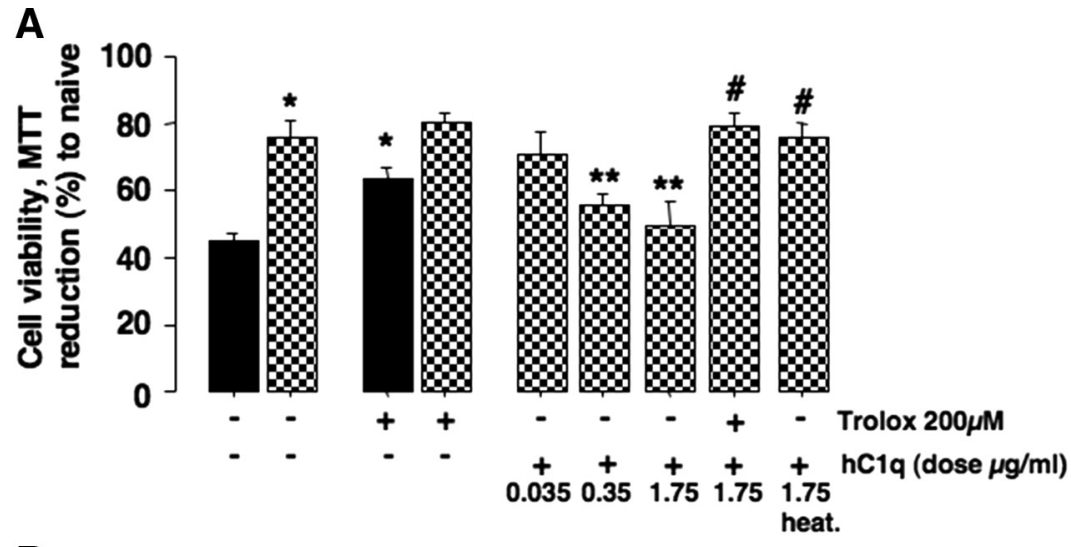

B
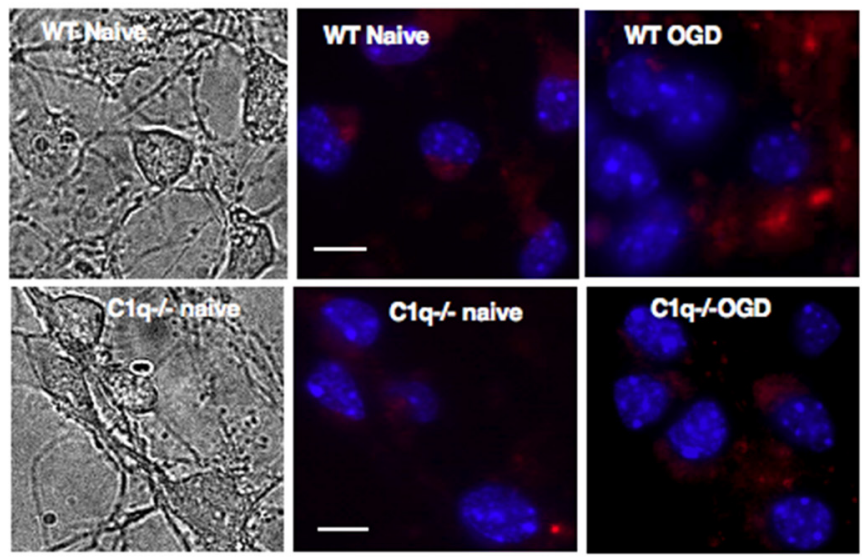

C

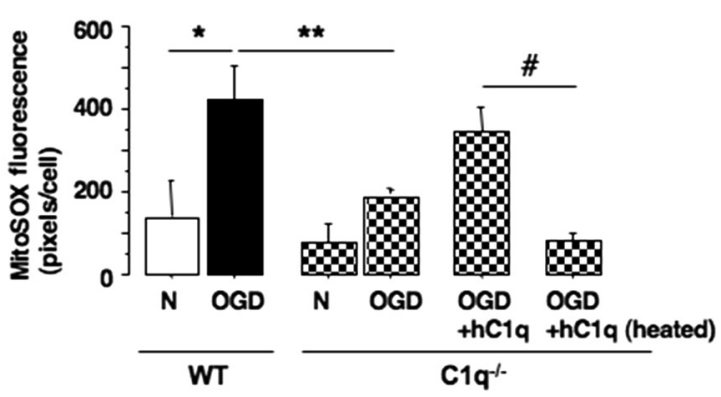

Figure 6. $A$, Cellular viability assessed at $20 \mathrm{~h}$ after $0 \mathrm{GD}$ in WT (black bar) and $\mathrm{C} 1 \mathrm{q}^{-1-}$ (checkered bar) neurons in the presence or the absence of Trolox (200 $\mu \mathrm{m}$ ) or different concentrations of hC1q (indicated). $N=12$ for each group (except C1q ${ }^{-1-} 0 \mathrm{GD}^{-}$ boiled hC1q, $n=9$ ). Custom-purified $\mathrm{hC} 1 \mathrm{q}$ was used in one and commercial hC1q in three experiments. Heat inactivation of $h C 1 q$ was achieved by boiling for $15 \mathrm{~min} .{ }^{*} p=0.0007$ compared with WT OGD-stressed cells; ${ }^{* *} p<0.002$ compared with $\mathrm{Clq}^{-1-}$ OGD-stressed cells; ${ }^{\#} p<0.0001$ compared with $\mathrm{C} \mathrm{q}^{-1-}$ OGD-stressed cells incubated with $1.75 \mu \mathrm{g} / \mathrm{ml} \mathrm{hC} 1 \mathrm{q}$. B, Confocal microscopy of live WT neurons stained with MitoSOX Red (red) before and at $60 \mathrm{~min}$ after $0 G \mathrm{G}$ and $\mathrm{C}_{\mathrm{q}}{ }^{-1-}$ neurons before and at $60 \mathrm{~min}$ after OGD preincubated with active or heat-inactivated hC1q. Scale bars, $10 \mu \mathrm{m}$. C, Semiquantitative analysis of MitoSOX fluorescence in live neurons; WT naive and OGD-stressed $(n=10), \mathrm{Clq}^{-1-}$ naive $(n=10), 0 \mathrm{GD}$-stressed $(n=10), \mathrm{C} 1 \mathrm{q}^{-1-}$ OGD-stressed and preincubated with active hC1q $(n=8)$, or heat-inactivated hC1q $(n=8)$ for 60 min of reperfusion. ${ }^{*} p=0.004$; ${ }^{* *} p=0.03 ;{ }^{*} p=0.002$. Error bars indicate SEM.

Fig. $1 I-K$, available at www.jneurosci.org as supplemental material). Thus, neither mitochondrial ROS scavenging capacity nor $\Delta \Psi \mathrm{m}$ account for the significantly decreased rate of mitochondrial ROS emission in $\mathrm{Clq}^{-/-}$mice compared with $\mathrm{Clq}^{+/+}$ counterparts. Although we do not know the exact molecular mechanism for C1q-mediated regulation of mitochondrial ROS release, this study is the first to demonstrate a pathophysiological significance of $\mathrm{Clq}$ in oxidative stress originated from mitochondria during HI damage in the developing brain. Compared with $\mathrm{Clq}^{+/+}$mice, $\mathrm{Clq}^{-/-}$mice exhibited significantly reduced extent of oxidative injury, suggesting that ROS of mitochondrial origin contribute to oxidative injury in $\mathrm{HI}$ brain. In $\mathrm{Clq}^{+/+}$mice, signs of oxidative injury coincided ( $4 \mathrm{~h}$ of reperfusion) with mitochondrial signs of a secondary energy failure (4-6h of reperfusion), evidenced by the secondary decline of phosphorylating respiration rates. We propose that, in immature brain, $\mathrm{Clq}$ amplifies a burst of mitochondrial ROS release during hypoxiaischemia and reperfusion, and exacerbates oxidative brain injury, leading to a greater inhibition of mitochondrial respiratory chain. The data obtained in adult $\mathrm{Clq}^{-/-}$ and $\mathrm{Clq}^{+/+}$mice serve as an argumentum a contrario for this hypothetical sequence of events. Brain mitochondria isolated from adult $\mathrm{Clq}^{-/-}$and $\mathrm{Clq}^{+/+}$mice exhibited similar rates of ROS emission, and mature $\mathrm{Clq}^{-1-}$ mice were not protected against HI injury. This suggests that the ability of $\mathrm{Clq}$ to exacerbate oxidative stress by accelerating mitochondrial ROS emission is developmentally regulated. Wang et al. (2009) recently reported a fundamental age-dependent difference in the role of mitochondrial permeability transition pore in propagation of apoptotic and necrotic neuronal death after hypoxia-ischemia.

Interestingly, in $8.76 \%$ of neuronal mitochondria examined after $\mathrm{HI}$ insult, $\mathrm{Clq}$ protein accumulated at a very high density. When isolated $\mathrm{Clq}^{-/-}$mitochondria were coincubated with hClq, Western blot analysis revealed redistribution of hC1q from the buffer to mitochondria. However, no changes were detected in the ROS emission rate. This suggests that direct interaction between mitochondria and hC1q exists; however, it requires an additional intracellular signaling to alter ROS generation. Thus, the significance for cellular fate of this relatively minor $(8.76 \%)$ fraction of mitochondria with dense $\mathrm{C} 1 \mathrm{q}$ accumulation remains unclear. Of note, the fraction of mitochondria that released apoptosis-inducing factor after hypoxiaischemia did not exceed 20\% in P5 and 10\% in P21 mice (Zhu et al., 2005), suggesting that the damage of only $10-20 \%$ of mitochondria is sufficient for execution of cellular death pathway after hypoxia-ischemia.

Our in vitro experiments support detrimental role of C1qmediated mitochondrial ROS release in $\mathrm{HI}$ brain injury. In $\mathrm{Clq}^{+/+}$ cells, OGD challenge increased mitochondrial ROS signal associated with significant cellular mortality, and the exposure to antioxidant, Trolox, improved cellular viability. Compared with $\mathrm{Clq}^{+/+}$cells, $\mathrm{Clq}^{-/-}$neurons exhibited a markedly reduced mitochondrial ROS signal coupled with significantly better viability after OGD. When during reperfusion the $\mathrm{Clq}^{-/-}$neurons were exposed to hC1q, cells exhibited a dose-dependent increase in their mortality rate, virtually turning $\mathrm{Clq}^{-1-}$ phenotype into $\mathrm{Clq}^{+/+}$phenotype with respect to OGD-induced mortality. 
This deleterious effect of hC1q on neuronal viability in OGDexposed $\mathrm{Clq}^{-1-}$ cells was fully abrogated by Trolox. Trolox is a vitamin $\mathrm{E}$ derivative used extensively in vitro and in vivo to dissect out the contribution of oxidative stress from other mechanisms of ischemic neuronal injury (Copin et al., 1998; Gupta and Sharma, 2006; Wang et al., 2008). Interestingly, the measurement of mitochondrial superoxide-specific signal in naive neurons did not demonstrate statistical significance between $\mathrm{Clq}^{-1-}$ and WT cells. However, in response to OGD, $\mathrm{Clq}^{-1-}$ cells exhibited significantly decreased mitochondrial superoxide fluorescence compared with OGD-stressed WT neurons. The difference in ROS emission rates between $\mathrm{WT}$ and $\mathrm{Clq}^{-1-}$ isolated mitochondria was detected using the FAD-linked substrate succinate. It is important to note that the difference in mitochondrial ROS signal was reproduced in $\mathrm{WT}$ and $\mathrm{Clq}^{-1-}$ live neurons only after OGD challenge. This suggests that, during reperfusion, neurons more actively oxidize succinate than NAD-linked substrates. It has been reported that brain ischemia and reperfusion in rats resulted in significant inhibition of mitochondrial respiration tested on NAD-linked substrates. However, no significant differences from the control values were detected when the same mitochondria respired on succinate (Sims, 1991). Similarly, in neonatal rats exposed to hypoxia-ischemia, cerebral mitochondria exhibited a better respiration on FAD-linked than on NAD-linked substrates (Gilland et al., 1998). This suggests that, compared with the C-I activity, the activity of C-II is better preserved after hypoxiaischemia, which makes succinate a preferred mitochondrial substrate on reperfusion. Importantly, succinate oxidation can support the highest rate of ROS production in mitochondria (for review, see Starkov, 2008). Specifically, only mitochondria isolated from the brain and the heart (not liver, kidney, or muscle) exhibit 10-fold increase in ROS emission rates obtained on succinate compared with glutamate, $\alpha$-ketoglutarate, glycerol phosphate, and palmitate carnitine (Tahara et al., 2009). Theoretically, mitochondria actively oxidizing succinate on reperfusion are capable of a dramatic increase in ROS-generating capacity leading to a reperfusion-driven oxidative burst.

In conclusion, this study uncovers the existence of a novel C1q-dependent pathway in regulation of mitochondrial production of ROS and oxidative stress in the developing brain subjected to hypoxia-ischemia. The central role of $\mathrm{Clq}$ in this pathway highlights a mechanistic link between two fundamental events initiated by ischemia-reperfusion: activation of innate immunity and oxidative stress. This study also shows that the classical C activation pathway does not exacerbate HI brain injury via activation of the terminal complex. Finally, this work not only uncovered C1q-dependent mechanism of oxidative damage in the developing brain but also dissected out a causative role for ROS of mitochondrial origin.

\section{References}

Abramov AY, Scorziello A, Duchen MR (2007) Three distinct mechanisms generate oxygen free radicals in neurons and contribute to cell death during anoxia and reoxygenation. J Neurosci 27:1129-1138.

Alexander JJ, Jacob A, Bao L, Macdonald RL, Quigg RJ (2005) Complementdependent apoptosis and inflammatory gene changes in murine lupus cerebritis. J Immunol 175:8312-8319.

Arumugam TV, Magnus T, Woodruff TM, Proctor LM, Shiels IA, Taylor SM (2006) Complement mediators in ischemia-reperfusion injury. Clin Chim Acta 374:33-45.

Baalasubramanian S, Harris CL, Donev RM, Mizuno M, Omidvar N, Song WC, Morgan BP (2004) CD59a is the primary regulator of membrane attack complex assembly in the mouse. J Immunol 173:3684-3692.

Benchenane K, Berezowski V, Fernández-Monreal M, Brillault J, Valable S, Dehouck MP, Cecchelli R, Vivien D, Touzani O, Ali C (2005) Oxygen glucose deprivation switches the transport of tPA across the blood-brain barrier from an LRP-dependent to an increased LRP-independent process. Stroke 36:1065-1070.

Benzi G, Arrigoni E, Marzatico F, Villa RF (1979) Influence of some biological pyrimidines on the succinate cycle during and after cerebral ischemia. Biochem Pharmacol 28:2545-2550.

Benzi G, Pastoris O, Dossena M (1982) Relationships between gammaaminobutyrate and succinate cycles during and after cerebral ischemia. J Neurosci Res 7:193-201.

Botto M, Dell'Agnola C, Bygrave AE, Thompson EM, Cook HT, Petry F, Loos M, Pandolfi PP, Walport MJ (1998) Homozygous C1q deficiency causes glomerulonephritis associated with multiple apoptotic bodies. Nat Genet 19:56-59.

Brewer GJ, Torricelli JR, Evege EK, Price PJ (1993) Optimized survival of hippocampal neurons in B27-supplemented Neurobasal, a new serumfree medium combination. J Neurosci Res 35:567-576.

Caspersen CS, Sosunov A, Utkina-Sosunova I, Ratner VI, Starkov AA, Ten VS (2008) An isolation method for assessment of brain mitochondria function in neonatal mice with hypoxic-ischemic brain injury. Dev Neurosci 30:319-324.

Chen Q, Moghaddas S, Hoppel CL, Lesnefsky EJ (2008) Ischemic defects in the electron transport chain increase the production of reactive oxygen species from isolated rat heart mitochondria. Am J Physiol Cell Physiol 294:C460-C466.

Copin JC, Li Y, Reola L, Chan PH (1998) Trolox and 6,7-dinitroquinoxaline2,3-dione prevent necrosis but not apoptosis in cultured neurons subjected to oxygen deprivation. Brain Res 784:25-36.

Cowell RM, Plane JM, Silverstein FS (2003) Complement activation contributes to hypoxic-ischemic brain injury in neonatal rats. J Neurosci 23:9459-9468.

Ferriero DM (2004) Neonatal brain injury. N Engl J Med 351:1985-1995.

Figueroa E, Gordon LE, Feldhoff PW, Lassiter HA (2005) The administration of cobra venom factor reduces post-ischemic cerebral injury in adult and neonatal rats. Neurosci Lett 380:48-53.

Folbergrová J, Ljunggren B, Norberg K, Siesjö BK (1974) Influence of complete ischemia on glycolytic metabolites, citric acid cycle intermediates, and associated amino acids in the rat cerebral cortex. Brain Res 80:265-279.

Gilland E, Puka-Sundvall M, Hillered L, Hagberg H (1998) Mitochondrial function and energy metabolism after hypoxia-ischemia in the immature rat brain: involvement of NMDA-receptors. J Cereb Blood Flow Metab 18:297-304.

Griffith OW (1980) Determination of glutathione and glutathione disulfide using glutathione reductase and 2-vinylpyridine. Anal Biochem 106:207-212.

Gupta S, Sharma SS (2006) Neuroprotective effects of Trolox in global cerebral ischemia in gerbils. Biol Pharm Bull 29:957-961.

Imm MD, Feldhoff PW, Feldhoff RC, Lassiter HA (2002) The administration of complement component $\mathrm{C} 9$ augments post-ischemic cerebral infarction volume in neonatal rats. Neurosci Lett 325:175-178.

Kabad E, Mayer M (1961) Experimental immunochemistry, Ed 2. Springfield, IL: Thomas.

Kirkland RA, Saavedra GM, Franklin JL (2007) Rapid activation of antioxidant defenses by nerve growth factor suppresses reactive oxygen species during neuronal apoptosis: evidence for a role in cytochrome $\mathrm{c}$ redistribution. J Neurosci 27:11315-11326.

Kowaltowski AJ, Cosso RG, Campos CB, Fiskum G (2002) Effect of Bcl-2 overexpression on mitochondrial structure and function. J Biol Chem 277:42802-42807.

Lafemina MJ, Sheldon RA, Ferriero DM (2006) Acute hypoxia-ischemia results in hydrogen peroxide accumulation in neonatal but not adult mouse brain. Pediatr Res 59:680-683.

Luo X, Weber GA, Zheng J, Gendelman HE, Ikezu T (2003) Clqcalreticulin induced oxidative neurotoxicity: relevance for the neuropathogenesis of Alzheimer's disease. J Neuroimmunol 135:62-71.

Mack WJ, Sughrue ME, Ducruet AF, Mocco J, Sosunov SA, Hassid BG, Silverberg JZ, Ten VS, Pinsky DJ, Connolly ES Jr (2006) Temporal pattern of Clq deposition after transient focal cerebral ischemia. J Neurosci Res 83:883-889.

Mocco J, Mack WJ, Ducruet AF, Sosunov SA, Sughrue ME, Hassid BG, Nair MN, Laufer I, Komotar RJ, Claire M, Holland H, Pinsky DJ, Connolly ES 
Jr (2006) Complement component C3 mediates inflammatory injury following focal cerebral ischemia. Circ Res 99:209-217.

Morgan BP, Chamberlain-Banoub J, Neal JW, Song W, Mizuno M, Harris CL (2006) The membrane attack pathway of complement drives pathology in passively induced experimental autoimmune myasthenia gravis in mice. Clin Exp Immunol 146:294-302.

Pedersen ED, Waje-Andreassen U, Vedeler CA, Aamodt G, Mollnes TE (2004) Systemic complement activation following human acute ischaemic stroke. Clin Exp Immunol 137:117-122.

Racay P, Tatarkova Z, Chomova M, Hatok J, Kaplan P, Dobrota D (2009) Mitochondrial calcium transport and mitochondrial dysfunction after global brain ischemia in rat hippocampus. Neurochem Res 34:14691478 .

Robinson KM, Janes MS, Beckman JS (2008) The selective detection of mitochondrial superoxide by live cell imaging. Nat Protoc 3:941-947.

Schäfer MK, Schwaeble WJ, Post C, Salvati P, Calabresi M, Sim RB, Petry F, Loos M, Weihe E (2000) Complement C1q is dramatically upregulated in brain microglia in response to transient global cerebral ischemia. J Immunol 164:5446-5452.

Schinzel AC, Takeuchi O, Huang Z, Fisher JK, Zhou Z, Rubens J, Hetz C, Danial NN, Moskowitz MA, Korsmeyer SJ (2005) Cyclophilin D is a component of mitochondrial permeability transition and mediates neuronal cell death after focal cerebral ischemia. Proc Natl Acad Sci U S A 102:12005-12010.

Schultz SJ, Aly H, Hasanen BM, Khashaba MT, Lear SC, Bendon RW, Gordon LE, Feldhoff PW, Lassiter HA (2005) Complement component 9 activation, consumption, and neuronal deposition in the post-hypoxicischemic central nervous system of human newborn infants. Neurosci Lett 378:1-6.

Shepherd D, Garland PB (1969) The kinetic properties of citrate synthase from rat liver mitochondria. Biochem J 114:597-610.

Simonyan RA, Skulachev VP (1998) Thermoregulatory uncoupling in heart muscle mitochondria: involvement of the ATP/ADP antiporter and uncoupling protein. FEBS Lett 436:81-84.

Sims NR (1991) Selective impairment of respiration in mitochondria isolated from brain subregions following transient forebrain ischemia in the rat. J Neurochem 56:1836-1844.

Singhrao SK, Neal JW, Rushmere NK, Morgan BP, Gasque P (2000) Spontaneous classical pathway activation and deficiency of membrane regulators render human neurons susceptible to complement lysis. Am J Pathol 157:905-918.

Smyth MD, Cribbs DH, Tenner AJ, Shankle WR, Dick M, Kesslak JP, Cotman CW (1994) Decreased levels of C1q in cerebrospinal fluid of living Alzheimer patients correlate with disease state. Neurobiol Aging 15:609-614

Starkov AA (2008) The role of mitochondria in reactive oxygen species metabolism and signaling. Ann N Y Acad Sci 1147:37-52.

Starkov AA, Fiskum G (2003) Regulation of brain mitochondrial H2O2 production by membrane potential and $\mathrm{NAD}(\mathrm{P}) \mathrm{H}$ redox state. J Neurochem 86:1101-1107.

Tahara EB, Navarete FD, Kowaltowski AJ (2009) Tissue-, substrate-, and site-specific characteristics of mitochondrial reactive oxygen species generation. Free Radic Biol Med 46:1283-1297.

Takuma K, Yao J, Huang J, Xu H, Chen X, Luddy J, Trillat AC, Stern DM, Arancio O, Yan SS (2005) ABAD enhances Abeta-induced cell stress via mitochondrial dysfunction. FASEB J 19:597-598.

Ten VS, Bradley-Moore M, Gingrich JA, Stark RI, Pinsky DJ (2003) Brain injury and neurofunctional deficit in neonatal mice with hypoxicischemic encephalopathy. Behav Brain Res 145:209-219.
Ten VS, Wu EX, Tang H, Bradley-Moore M, Fedarau MV, Ratner VI, Stark RI, Gingrich JA, Pinsky DJ (2004) Late measures of brain injury after neonatal hypoxia-ischemia in mice. Stroke 35:2183-2188.

Ten VS, Sosunov SA, Mazer SP, Stark RI, Caspersen C, Sughrue ME, Botto M, Connolly ES Jr, Pinsky DJ (2005) C1q-deficiency is neuroprotective against hypoxic-ischemic brain injury in neonatal mice. Stroke 36:22442250.

Tenner AJ, Lesavre PH, Cooper NR (1981) Purification and radiolabeling of human C1q. J Immunol 127:648-653.

Tohgi H, Utsugisawa K, Nagane Y (2000) Hypoxia-induced expression of $\mathrm{C} 1 \mathrm{q}$, a subcomponent of the complement system, in cultured rat PC12 cells. Neurosci Lett 291:151-154.

Trouw LA, Blom AM, Gasque P (2008) Role of complement and complement regulators in the removal of apoptotic cells. Mol Immunol 45:1199-1207.

Vakeva AP, Agah A, Rollins SA, Matis LA, Li L, Stahl GL (1998) Myocardial infarction and apoptosis after myocardial ischemia and reperfusion: role of the terminal complement components and inhibition by anti-C5 therapy. Circulation 97:2259-2267.

Van Beek J, Bernaudin M, Petit E, Gasque P, Nouvelot A, MacKenzie ET, Fontaine M (2000) Expression of receptors for complement anaphylatoxins C3a and C5a following permanent focal cerebral ischemia in the mouse. Exp Neurol 161:373-382.

Wang HK, Park UJ, Kim SY, Lee JH, Kim SU, Gwag BJ, Lee YB (2008) Free radical production in CA1 neurons induces MIP- $1 \alpha$ expression, microglia recruitment, and delayed neuronal death after transient forebrain ischemia. J Neurosci 28:1721-1727.

Wang X, Carlsson Y, Basso E, Zhu C, Rousset CI, Rasola A, Johansson BR, Blomgren K, Mallard C, Bernardi P, Forte MA, Hagberg H (2009) Developmental shift of cyclophilin D contribution to hypoxic-ischemic brain injury. J Neurosci 29:2588-2596.

Yamada K, Miwa T, Liu J, Nangaku M, Song WC (2004) Critical protection from renal ischemia reperfusion injury by CD55 and CD59. J Immunol 172:3869-3875.

Zanotti A, Azzone GF (1980) Safranine as membrane potential probe in rat liver mitochondria. Arch Biochem Biophys 201:255-265.

Zhang WH, Wang X, Narayanan M, Zhang Y, Huo C, Reed JC, Friedlander RM (2003) Fundamental role of the Rip2/caspase-1 pathway in hypoxia and ischemia-induced neuronal cell death. Proc Natl Acad Sci U S A 100:16012-16017.

Zhou W, Farrar CA, Abe K, Pratt JR, Marsh JE, Wang Y, Stahl GL, Sacks SH (2000) Predominant role for C5b-9 in renal ischemia/reperfusion injury. J Clin Invest 105:1363-1371.

Zhu C, Wang X, Xu F, Bahr BA, Shibata M, Uchiyama Y, Hagberg H, Blomgren K (2005) The influence of age on apoptotic and other mechanisms of cell death after cerebral hypoxia-ischemia. Cell Death Differ $12: 162-176$.

Zhu C, Xu F, Fukuda A, Wang X, Fukuda H, Korhonen L, Hagberg H, Lannering B, Nilsson M, Eriksson PS, Northington FJ, Björk-Eriksson T, Lindholm D, Blomgren K (2007) X chromosome-linked inhibitor of apoptosis protein reduces oxidative stress after cerebral irradiation or hypoxia-ischemia through up-regulation of mitochondrial antioxidants. Eur J Neurosci 26:3402-3410.

Zhu C, Qiu L, Wang X, Xu F, Nilsson M, Cooper-Kuhn C, Kuhn HG, Blomgren K (2009) Age-dependent regenerative responses in the striatum and cortex after hypoxia-ischemia. J Cereb Blood Flow Metab 29: 342-354. 